\title{
Identification of new participants in the rainbow trout (Oncorhynchus mykiss) oocyte maturation and ovulation processes using cDNA microarrays
}

\author{
Julien Bobe*, Jerôme Montfort, Thaovi Nguyen and Alexis Fostier
}

Address: Institut National de la Recherche Agronomique, INRA-SCRIBE, IFR 140, Campus de Beaulieu, 35000 Rennes Cedex, France

Email: Julien Bobe* - Julien.Bobe@rennes.inra.fr; Jerôme Montfort - Jerome.Montfort@rennes.inra.fr; Thaovi Nguyen - Thao-

Vi.Nguyen@rennes.inra.fr; Alexis Fostier - Alexis.Fostier@rennes.inra.fr

* Corresponding author

Published: 27 July 2006

Reproductive Biology and Endocrinology 2006, 4:39 doi:10.1/86/1477-7827-4-39

This article is available from: http://www.rbej.com/content/4/I/39

(c) 2006 Bobe et al; licensee BioMed Central Ltd.

This is an Open Access article distributed under the terms of the Creative Commons Attribution License (http://creativecommons.org/licenses/by/2.0), which permits unrestricted use, distribution, and reproduction in any medium, provided the original work is properly cited.
Received: 15 June 2006

Accepted: 27 July 2006

\begin{abstract}
Background: The hormonal control of oocyte maturation and ovulation as well as the molecular mechanisms of nuclear maturation have been thoroughly studied in fish. In contrast, the other molecular events occurring in the ovary during post-vitellogenesis have received far less attention.

Methods: Nylon microarrays displaying 9152 rainbow trout cDNAs were hybridized using RNA samples originating from ovarian tissue collected during late vitellogenesis, post-vitellogenesis and oocyte maturation. Differentially expressed genes were identified using a statistical analysis. A supervised clustering analysis was performed using only differentially expressed genes in order to identify gene clusters exhibiting similar expression profiles. In addition, specific genes were selected and their preovulatory ovarian expression was analyzed using real-time PCR.

Results: From the statistical analysis, 310 differentially expressed genes were identified. Among those genes, 90 were up-regulated at the time of oocyte maturation while 220 exhibited an opposite pattern. After clustering analysis, 90 clones belonging to 3 gene clusters exhibiting the most remarkable expression patterns were kept for further analysis. Using real-time PCR analysis, we observed a strong up-regulation of ion and water transport genes such as aquaporin 4 (aqp4) and pendrin (slc26). In addition, a dramatic up-regulation of vasotocin (avt) gene was observed. Furthermore, angiotensin-converting-enzyme 2 (ace2), coagulation factor $V$ (cf5), adam 22, and the chemokine cxcll4 genes exhibited a sharp upregulation at the time of oocyte maturation. Finally, ovarian aromatase (cypl9al) exhibited a dramatic down-regulation over the post-vitellogenic period while a down-regulation of Cytidine monophosphate$\mathrm{N}$-acetylneuraminic acid hydroxylase ( $\mathrm{cmah}$ ) was observed at the time of oocyte maturation.

Conclusion: We showed the over or under expression of more that 300 genes, most of them being previously unstudied or unknown in the fish preovulatory ovary. Our data confirmed the down-regulation of estrogen synthesis genes during the preovulatory period. In addition, the strong up-regulation of aqp 4 and slc26 genes prior to ovulation suggests their participation in the oocyte hydration process occurring at that time. Furthermore, among the most up-regulated clones, several genes such as cxcl14, ace2, adam22, cf5 have pro-inflammatory, vasodilatory, proteolytics and coagulatory functions. The identity and expression patterns of those genes support the theory comparing ovulation to an inflammatory-like reaction.
\end{abstract}




\section{Background}

In fish, as in other lower vertebrates, the post-vitellogenic period is very important for the completion of the oogenetic process. During this step, the follicle-enclosed postvitellogenic oocyte undergoes several key events such as the final acquisition of the ability to resume meiosis in response to the maturation-inducing steroid (MIS), the resumption of the meiotic process and, finally, its release from the surrounding follicular layers. In addition, the whole follicle (oocyte and surrounding follicular cells) undergoes a progressive differentiation ultimately leading to the release of a metaphase 2 oocyte. The key hormonal and molecular events involved in the control of meiosis resumption have been thoroughly studied and many studies have been dedicated to the action of gonadotropins, the regulation of steroidogenenic events and the action of the MIS (see [1-6] for review). However, the associated follicular or extra-follicular events involved in concomitant processes such as oocyte-follicular cells cross talk and ovulationmechanisms have received far less attention. Nevertheless, several researchgroups have studied the periovulatory ovarian physiology using classical biochemical or histological tools and, later, molecular approaches. Thus, several studies have dealt with ovarian proteases in their participation in the ovulatory process [7-9]. Differential display PCR and suppressive subtractive hybridization ( $\mathrm{SSH}$ ) approaches have also been developed in order to identify new differentially regulated genes in the fish periovulatory ovary [10-13]. In addition, numerous candidate gene studies have also been performed in the fish periovulatory ovary. Apart from genes related to hormonal controls, these studies were mostly dedicated to some specific gene families such as TGF beta family $[14,15]$ or connexins $[16,17]$. Finally, fewer studies have simultaneously analyzed the expression profiles of several genes belonging to different families [18,19]. However, in contrast to other biological processes, such as immune response [20], the post-vitellogenic period has never benefited from genome-wide transcriptomic studies that could provide a global view of the molecular events occurring in the post-vitellogenic ovary undergoing oocyte maturation. In this context, the present study aimed at performing a transcriptomic analysis of the postvitellogenic rainbow (Oncorhynchus mykiss) trout ovary. In order to do so, 9152-gene rainbow trout cDNA microarrays were hybridized using RNA samples originating from rainbow trout ovarian tissue collected during late vitellogenesis, post-vitellogenesis and oocyte maturation. A statistical analysis was performed in order to identify all the genes exhibiting a differential expression over this period. In addition, a supervised clustering analysis was performed using only the differentially expressed genes in order to identify groups (or clusters) of genes exhibiting similar expression profiles. Furthermore, as a first step in a long-term transcriptomic analysis of the rainbow trout post-vitellogenic ovary, we deliberately chose to focus on 3 gene clusters exhibiting the most remarkable expression patterns. Finally, specific genes were selected in each cluster based on the novelty of their putative identity and/or function. For each gene, a real-time PCR analysis of their ovarian expression profiles was performed using additional ovarian RNA samples.

\section{Methods \\ Animal and tissue collection}

Investigations were conducted according to the guiding principles for the use and care of laboratory animals and in compliance with French and European regulations on animal welfare. Two year old female rainbow trout (Oncorhynchus mykiss) were obtained during their first reproductive season from our experimental fish farm (Sizun, France) and held under natural photoperiod in a re-circulated water system in INRA experimental facilities (Rennes, France). The water temperature was kept constant at $12^{\circ} \mathrm{C}$. Ovaries were sampled from individual females during late vitellogenesis $(N=6)$, post-vitellogenesis $(\mathrm{N}=6)$ and during oocyte maturation $(\mathrm{N}=6)$. Oocyte developmental stage was assessed under binocular microscope according to previously described criteria [21,22]. Late vitellogenic samples were collected at the end of the vitellogenic process, approximately 3-4 weeks before expected ovulation. At this stage, germinal vesicle is not visible and no polarized cytoplasm area can be observed. Post-vitellogenic samples were collected 2-3 weeks later but before any noticeable morphological changes in yolk structure due to the process of meiosis resumption. At this stage, oocytes can display a subperipheral or peripheral germinal vesicle. When germinal vesicle is not visible, a dark mass of polarized cytoplasm can be observed. Oocyte maturation samples were collected after meiosis resumption. Those samples were thus collected after yolk clarification and around the time of germinal vesicle breakdown (GVBD). For tissue collection, trout were deeply anesthetized in 2-phenoxyethanol, killed by a blow on the head and bled by gill arch section. Ovaries were then dissected out of the body cavity under sterile conditions. Ovarian aliquots were frozen in liquid nitrogen and stored at $-80^{\circ} \mathrm{C}$ until RNA extraction.

\section{RNA extraction and reverse transcription}

Ovarian tissue was homogenized in Trizol reagent (Invitrogen, Cergy Pontoise, France) at a ratio of $100 \mathrm{mg}$ per $\mathrm{ml}$ of reagent and total RNA was extracted according to manufacturer's instruction. Due to yolk abundance in rainbow trout full-grown oocytes, total RNA was subsequently repurified using a Nucleospin RNA 2 kit (Macherey Nagel, Germany) to obtain genomic grade RNA quality. 


\section{cDNA microarrays}

Nylon micro-arrays $(7.6 \times 2.6 \mathrm{~cm})$ were obtained from INRA-GADIE (Jouy-en-Josas, France) [23]. A set of 9152 distinct rainbow trout cDNA clones originating from a pooled-tissues library [24] were spotted in duplicates after PCR amplification. PCR products were spotted onto Hybond $\mathrm{N}+$ membranes as described by Nguyen et al. [25]. This rainbow trout generic array was deposited in Gene Expression Omnibus (GEO) database (Platform\# GPL 3650) [26].

\section{Hybridization}

RNA samples originating from 13 ovarian samples (late vitellogenesis, $\mathrm{N}=3$; post-vitellogenesis, $\mathrm{N}=4$ and oocyte maturation $\mathrm{N}=6$ ) were used for microarray hybridization according to the following procedure. Hybridizations were carried out as described by Bertucci et al. [27], with minor modifications, at INRA AGENAE genomic facility (Rennes). A first hybridization was performed using a 33P-labelled oligonucleotide (TAATACGACTCACTATAGGG which is present at the extremity of each PCR product) to monitor the amount of cDNA in each spot. After stripping ( 3 hours $68^{\circ} \mathrm{C}, 0.1 \times \mathrm{SSC}, 0.2 \%$ SDS), arrays were prehybridized for $1 \mathrm{~h}$ at $65^{\circ} \mathrm{C}$ in hybridization solution ( $5 \times$ Denhardt's, $5 \times$ SSC, $0.5 \%$ SDS). Complex probes were prepared from $3 \mu \mathrm{g}$ of RNA of each sample by simultaneous reverse transcription and labeling for 1 hour at $42^{\circ} \mathrm{C}$ in the presence of $50 \mu \mathrm{Ci}$ [alpha-33P] dCTP, $5 \mu \mathrm{M}$ dCTP, $0.8 \mathrm{mM}$ each dATP, dTTP, dGTP and 200 units M-MLV SuperScript RNase H-reverse transcriptase (GIBCO BRL) in $30 \mu \mathrm{L}$ final volume. RNA was degraded by treatment at $68^{\circ} \mathrm{C}$ for $30 \mathrm{~min}$ with $1 \mu \mathrm{l} 10 \%$ SDS, $1 \mu \mathrm{l} 0.5 \mathrm{M}$ EDTA and $3 \mu \mathrm{l} 3 \mathrm{M} \mathrm{NaOH}$, and then equilibrated at room temperature for $15 \mathrm{~min}$. Neutralization was done by adding $10 \mu \mathrm{l}$ $1 \mathrm{M}$ Tris- $\mathrm{HCl}$ plus $3 \mu \mathrm{l} 2 \mathrm{~N} \mathrm{HCl}$. Arrays were incubated with the corresponding denatured labeled cDNAs for $18 \mathrm{~h}$ at $65^{\circ} \mathrm{C}$ in hybridization solution. After 3 washes ( 1 hours $68^{\circ} \mathrm{C}, 0.1 \times$ SSC $0.2 \%$ SDS), arrays were exposed 65 hours to phosphor-imaging plates before scanning using a FUJI BAS 5000. Signal intensities were quantified using ArrayGauge software (FujifilmMedical Systems, Stanford, CT) and deposited in GEO database (Series\# GSE 4871).

\section{Microarray signal processing}

Low oligonucleotide signals (lower than three times the background level) were excluded from the analysis. After this filtering step, signal processing was performed using the vector oligonucleotide data to correct each spot signal by the actual amount of DNA present in each spot. After correction, signal was normalized by dividing each gene expression value by the median value of the array.

\section{Microarray data analysis}

A statistical analysis was performed in order to identify differentially expressed genes between late vitellogenic, post-vitellogenic and maturing groups using SAM software[28]. Three 2-by-2 statistical analyses were performed in order to compare each group with the two other ones. In addition, a comparison was performed between samples taken prior to meiosis resumption (from late and post-vitellogenic females, $\mathrm{N}=7$ ) and during oocyte maturation $(\mathrm{N}=6)$. For each comparison, the lowest false discovery rate (FDR) was used to identify differentially abundant genes. All genes identified in at least one of the above comparisons were kept for clustering analysis in order to characterize the expression profiles of statistically relevant genes. For supervised clustering analysis [29], data was log transformed, median-centered and an average linkage clustering was performed using CLUSTER software [29]. Clusters were visualized using TREEVIEW software [29].

\section{Data mining}

Rainbow trout sequences originating from INRA Agenae [24] and USDA [30] EST sequencing programs were used to generate publicly available contigs [31]. The 8 th version (Om.8, released January 2006) was used for BlastX [32] comparison against the Swiss-Prot database (January 2006) [33]. The score of each alignment was retrieved after performing a BlastX comparison. In addition, for each EST spotted onto the membrane, the accession number of the corresponding rainbow trout cluster (Unigene Trout, January 2006), if any, was retrieved from the UniGene database [34].

\section{Real-time PCR analysis}

Real-time PCR was performed using all RNA $(\mathrm{N}=18)$ samples including those used for microarray analysis. Several over and under expressed clones belonging to three selected remarkable clusters, were selected according to their putative identity and/or function for analysis. Reverse transcription and real time PCR were performed as previously described [19]. Briefly, $3 \mu \mathrm{g}$ of total RNA were reverse transcribed using 200 units of Moloney murine Leukemia virus (MMLV) reverse transcriptase (Promega, Madison, WI) and $0.5 \mu \mathrm{g}$ random hexamers (Promega) per $\mu \mathrm{g}$ of total RNA according to manufacturer's instruction. RNA and dNTPs were denatured for 6 min at $70^{\circ} \mathrm{C}$, then chilled on ice for $5 \mathrm{~min}$ before the reverse transcription master mix was added. Reverse transcription was performed at $37^{\circ} \mathrm{C}$ for 1 hour and $15 \mathrm{~min}$ followed by a $15 \mathrm{~min}$ incubation step at $70^{\circ} \mathrm{C}$. Control reactions were run without $M M L V$ reverse transcriptase and used as negative controls in the real-time PCR study. Real-time PCR experiments were conducted using an I-Cycler IQ (Biorad, Hercules, CA). Reverse transcription products were diluted to $1 / 25$, and $5 \mu$ l were used for each real-time PCR reaction. Triplicates were run for each RT product. Real-time PCR was performed using a real-time PCR kit provided with a SYBR Green fluorophore (Euro- 
gentec, Belgium) according to the manufacturer's instructions and using $600 \mathrm{nM}$ of each primer. After a $2 \mathrm{~min}$ incubation step at $50^{\circ} \mathrm{C}$ and a $10 \mathrm{~min}$ incubation step at $95^{\circ} \mathrm{C}$, the amplification was performed using the following cycle: $95^{\circ} \mathrm{C}, 20 \mathrm{sec} ; 60^{\circ} \mathrm{C}, 1 \mathrm{~min}, 40$ times. For all primer pairs, the relative abundance of target cDNA within sample set was calculated from a serially diluted ovarian cDNA pool using the I-Cycler IQ software. This dilution curve was used to ensure that PCR efficiency was within an $80-100 \%$ range and that amplification was linear within sample set. After amplification, a fusion curve was obtained using the following protocol: $10 \mathrm{sec}$ holding followed by a $0.5^{\circ} \mathrm{C}$ increase, repeated 80 times and starting at $55^{\circ} \mathrm{C}$. The level of $18 \mathrm{~S}$ RNA in each sample was measured and used for target genes abundance normalization within sample set. In addition to the genes identified from the transcriptomic analysis, a widely used standard gene, elongation factor 1 alpha $(e f 1 \alpha)$, was monitored using the same sample set to validate the normalization procedure. GenBank accession number and primer sequences are shown in table 1 . Statistical analyses were performed using Statistica 7.0 software (Statsoft, Tulsa, OK). Differences between ovarian developments stages were analyzed using non parametric U tests.

\section{Results \\ Statistical analysis and supervised clustering}

After signal processing, 8263 clones out of 9152 were kept for further analysis. From the statistical analysis, 310 clones were found to exhibit a differential abundance between at least 2 of the studied ovarian stages (late vitellogenesis, post-vitellogenesis and oocyte maturation). For all SAM analyses performed, the false discovery rate (FDR) was always lower than $0.7 \%$. Among the 310 identified clones, 90 were up-regulated during oocyte maturation while 220 exhibited an opposite pattern. A clustering analysis was performed using only expression data of the 310 identified clones in order to characterize the expression profiles of those genes. The clustering analysis clearly separated the over from the under expressed genes (Figure $1)$. The number of each clone (1-310) in the clustering analysis (Figure 1) was kept in subsequent tables 1, 2, 3, 4 and in the text. Within down-regulated genes, a cluster of 32 genes (cluster 1, Figure 1) was characterized by high expression levels during late vitellogenesis, low levels during oocyte maturation and intermediate or variable levels during post-vitellogenesis (Figure 1). Within up-regulated clones, a cluster of 44 genes (cluster 2, Figure 1) was characterized by a strong over expression at the time of meiosis resumption while a cluster of 14 genes (cluster 3, Figure 1) exhibited a very low expression during late and post-vitellogenesis and an up-regulation before meiosis resumption (Figure 1).

Table I: Primer used for the real-time PCR study. For each target gene, full and abbreviated names, GenBank accession number of the corresponding rainbow trout sequence and primer sequences are shown. The clone \# is consistent with clone numbering in Figure I and Tables 2-4.

\begin{tabular}{|c|c|c|c|c|c|}
\hline Target gene & $\begin{array}{c}\text { Abbreviated } \\
\text { name }\end{array}$ & GenBank \# & Clone \# & Forward sequence & Reverse sequence \\
\hline ovarian aromatase & cyp/9al & $\underline{B} \times 083177$ & $\begin{array}{l}196 \\
198\end{array}$ & СТСТССТСTCATACСTCAGGTT & AGAGGAACTGCTGAGTATGAAT \\
\hline $\begin{array}{l}\text { vitamin } \mathrm{K} \text { dependent } \\
\text { protein } \mathrm{S} \text { precursor }\end{array}$ & protein $S$ & $\underline{\mathrm{B} X 320624}$ & $\begin{array}{l}199 \\
200\end{array}$ & ACATGTGGGGGATGTTCATT & GAGGCCATGTTACGGTTTTG \\
\hline $\begin{array}{c}\text { Cytidine } \\
\text { monophosphate-N- } \\
\text { acetylneuraminic acid } \\
\text { hydroxylase }\end{array}$ & cmah & $\underline{B} \times 8784 \mid 4$ & 212 & GGAGGCCTGTTCATCAAAGA & CCTGTGTGAAGCTGTCAGGA \\
\hline coagulation factor $V$ & $c f 5$ & BX879767 & 235 & AGGGACACACACACACATCC & GAGTTACTGCACGCACCTGA \\
\hline $\begin{array}{l}\text { pendrin or solute } \\
\text { carrier family } 26\end{array}$ & slc26 & BX873066 & 236 & CATGCATGGATTCATGGAATAA & TGGATTGGGTGACATCAACA \\
\hline vasotocin & avt & CA375992 & 238 & GAGGCTGGAGGAAGAGTGTG & TTCTGTTTGCTGGGTGACTG \\
\hline $\begin{array}{c}\text { angiotensin-converting } \\
\text { enzyme } 2\end{array}$ & ace2 & BX867294 & 245 & AACAACAGGAAGCCAGGATG & CGTTCCACATGTATGCCTTG \\
\hline CXC chemokine LI4 & cxcll 4 & BX868653 & 250 & CAAAGGGAACGAGTGAGAGAA & GCCTGATGGCCAACTTAAAC \\
\hline $\begin{array}{l}\text { A Disintegrin And } \\
\text { Metalloproteinases } 22\end{array}$ & adam 22 & $\overline{\mathrm{CA} 363158}$ & 258 & CCCGACTAGGAGAGTTGCAG & ATCATCACATGACCCCCACT \\
\hline serine protease 23 & $s p 23$ & BX087643 & 296 & ACTGCCGAGAAGGATGAAGA & CCTCAGCAAGGGAAGTGAAG \\
\hline aquaporin 4 & aqp 4 & $\underline{B \times 8852 \mid 4}$ & $\begin{array}{l}305 \\
306\end{array}$ & TGTCATTACCAGCCAACTGC & TGAGACAGCCCTCCAGAAGT \\
\hline $\begin{array}{c}\text { elongation factor I } \\
\text { alpha }\end{array}$ & efl $\alpha$ & AF498320 & & AGCGCAATCAGCCTGAGAGGTA & GCTGGACAAGCTGAAGGCTGAG \\
\hline I8S ribosomal RNA & 185 & AF308535 & & CGGAGGTTCGAAGACGATCA & TCGCTAGTTGGCATCGTTTAT \\
\hline
\end{tabular}




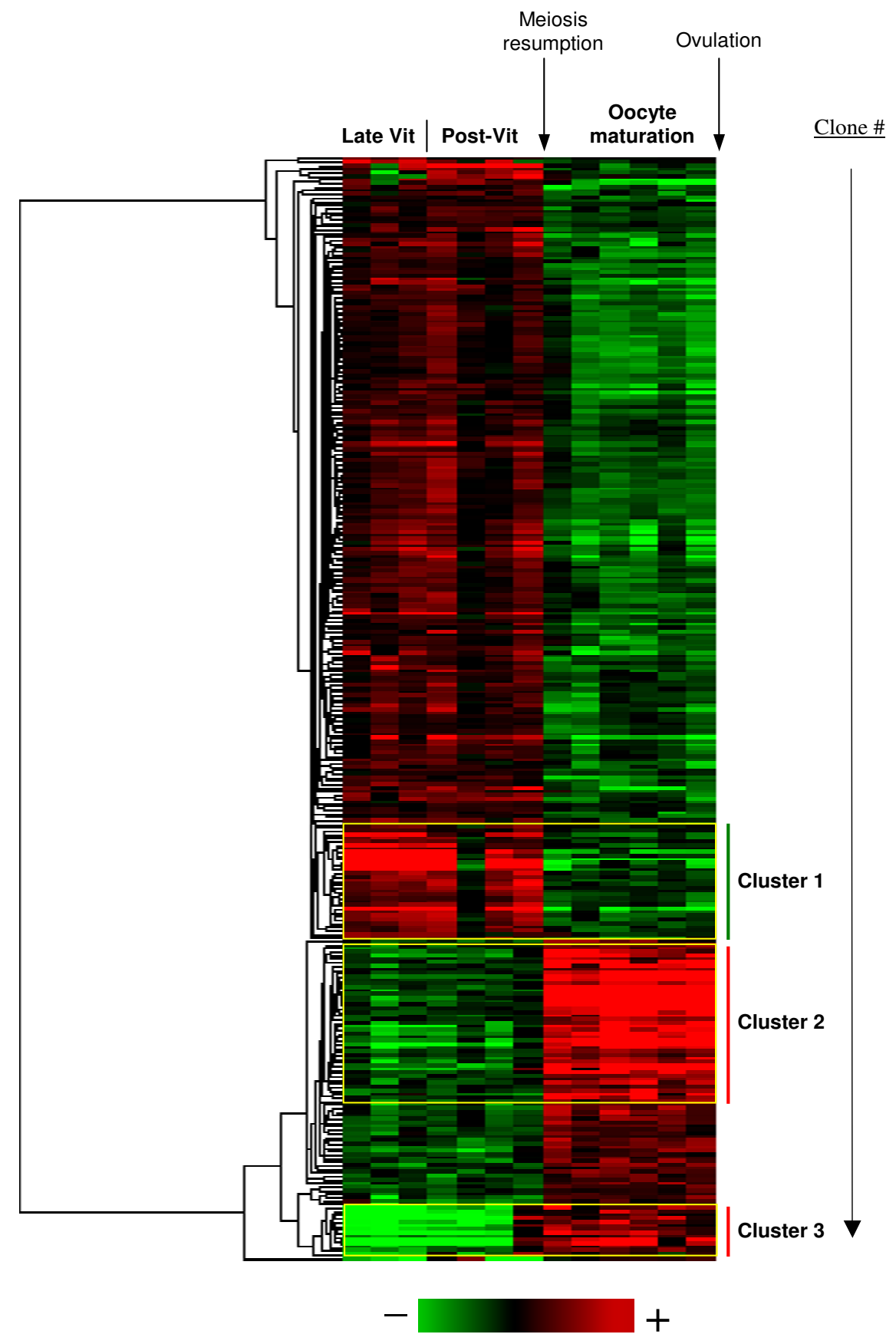

Figure I

Supervised average linkage clustering analysis of 310 genes in the rainbow trout ovary during late vitellogenesis (Late Vit), post vitellogenesis (post-Vit) and oocyte maturation. Each row represents a gene and each column represents an ovarian RNA sample. The dendrogram on the left represents correlation distances between the profiles of studied genes. The 17 samples are supervised according to the natural time-course of oogenesis. For each gene the expression level within sample set is indicated using a color intensity scale. Red and green are used for over and under expression respectively while black is used for median expression. 
Table 2: Differentially regulated clones belonging to cluster I.

\begin{tabular}{|c|c|c|c|c|c|c|}
\hline Clone name & \# & GenBank & Sigenae contig & Swissprot_hit_description & Score & Unigene \\
\hline tcac0002.b. 13 & 189 & $\underline{\mathrm{B} X 081818}$ & tcac0002c.b.13_3.I.s.om.8 & $\begin{array}{l}\text { YBOXI_RAT (P6296I) Nuclease sensitive element } \\
\text { binding protein I (Y-box binding protein I) (YB-I) }\end{array}$ & 528 & Omy.6894 \\
\hline tcay0023.c.II & 190 & $\underline{B \times 311374}$ & tcav0002c.e.18_3.I.s.om.8 & $\begin{array}{l}\text { IF2B_HUMAN (P20042) Eukaryotic translation } \\
\text { initiation factor } 2 \text { subunit } 2 \text { (elF-2-beta) }\end{array}$ & 1096 & Omy.8419 \\
\hline tcay0023.a. 19 & 191 & $\underline{\mathrm{B} X 310198}$ & $\begin{array}{l}\text { tcay0023b.a.19_3.I.s.om.8 } \\
\text { tcay0002b.h.16_3.I.s.om.8 }\end{array}$ & $\begin{array}{l}\text { STIS3_BRARE (Q7T2V2) Cytosolic } \\
\text { sulfotransferase } 3 \text { (EC 2.8.2.-) (SULTI ST3) }\end{array}$ & 1267 & Omy. 9054 \\
\hline tcba0022.f.09 & 192 & BX868083 & tcay002Ib.I.08_3.I.s.om.8 & $\begin{array}{l}\text { NCPR_SALTR (PI96I8) NADPH - cytochrome } \\
\text { P450 reductase (EC I.6.2.4) (CPR) (P450R) } \\
\text { (Fragments) }\end{array}$ & 1536 & Omy.22976 \\
\hline tcay00 I7.I.02 & 193 & $\underline{\mathrm{B} X 307506}$ & $\begin{array}{l}\text { tcay00 I7b.I.02_3.I.s.om.8 } \\
\text { tcay00 I 7b.I.02_5.I.s.om.8 }\end{array}$ & $\begin{array}{l}\text { NIPM_HUMAN (O43920) NADH-ubiquinone } \\
\text { oxidoreductase I } 5 \mathrm{kDa} \text { subunit (EC I.6.5.3) (EC } \\
\text { I.6.99.3) }\end{array}$ & 382 & Omy.3888 \\
\hline tcac0006.f. 17 & 194 & $\underline{B \times 085016}$ & $\begin{array}{l}\text { tcac0006c.f.17_5.I.s.om.8 } \\
\text { tcac000Ic.e.23_3.I.s.om.8 }\end{array}$ & $\begin{array}{l}\text { CP2J3_RAT (P5I590) Cytochrome P450 2J3 (EC } \\
\text { I.I4.14.I) (CYPIIJ3) }\end{array}$ & 712 & Omy. 18165 \\
\hline tcba0023.m.01 & 195 & BX867932 & tcay00I0b.o.13_3.I.s.om.8 & $\begin{array}{l}\text { EXOS3_HUMAN (Q9NQT5) Exosome complex } \\
\text { exonuclease RRP40 (EC 3.1.13) }\end{array}$ & 668 & Omy.7234 \\
\hline tcac0004.f.2I & 196 & BX083177 & $\begin{array}{l}\text { tcac0004c.f.2I_5.I.s.om.8 } \\
\text { tcac0004c.f.2I_3.I.s.om.8 }\end{array}$ & $\begin{array}{l}\text { CPI9A_ORYLA (Q92087) Cytochrome P450 } \\
\text { I9AI (EC I.I4.I4.I) (Aromatase) (CYPXIX) } \\
\text { (Estrogen synthetase) (P-450AROM) }\end{array}$ & 879 & Omy.24I \\
\hline tcac0002.f.II & 197 & BX081889 & tcac0002c.f.II_3.I.s.om.8 & $\begin{array}{l}\text { RNPC2_HUMAN (Q I 4498) RNA-binding region } \\
\text { containing protein } 2 \text { (Hepatocellular carcinoma } \\
\text { protein I) (Splicing factor } \mathrm{HCCl} \text { ) }\end{array}$ & 1708 & Omy. 1045 \\
\hline tcbk00I3.n.I6 & 198 & BX876154 & tcac0004c.f.2I_3.I.s.om.8 & $\begin{array}{l}\text { CPI9A_ORYLA (Q92087) Cytochrome P450 } \\
\text { I9AI (EC I.I4.I4.I) (Aromatase) (CYPXIX) } \\
\text { (Estrogen synthetase) (P-450AROM) }\end{array}$ & 879 & Omy.24I \\
\hline tcbk0006.j.0I & 199 & BX874921 & tcav0003c.p.16_5.I.s.om.8 & $\begin{array}{l}\text { PROS_BOVIN (P07224) Vitamin K-dependent } \\
\text { protein S precursor }\end{array}$ & 415 & Omy.4204 \\
\hline tcay0036.n.19 & 200 & $\mathrm{~B} \times 320625$ & $\begin{array}{l}\text { tcav0003c.p.16_3.I.s.om.8 } \\
\text { tcav0003c.p.16_5.I.s.om.8 }\end{array}$ & $\begin{array}{l}\text { PROS_BOVIN (P07224) Vitamin K-dependent } \\
\text { protein S precursor }\end{array}$ & 415 & Omy.4204 \\
\hline tcba0006.1.19 & 201 & BX860777 & tcay0018b.i.17_3.I.s.om.8 & $\begin{array}{l}\text { TFRI_CRIGR (Q0789I) Transferrin receptor } \\
\text { protein I (TfRI) (TR) (TfR) (Trfr) }\end{array}$ & 968 & Omy. 16719 \\
\hline tcag0002.n.03 & 202 & СТ962587 & tcag0002b.n.03_5.I.s.om.8 & $\begin{array}{l}\text { CPIA3_ONCMY (Q92I09) Cytochrome P450 } \\
\text { IA3 (EC I.14.14.I) (CYPIA3) (CYPIAI) }\end{array}$ & 2563 & Omy. II 1738 \\
\hline tcab0003.h.2I & 203 & $\underline{\mathrm{B} \times 080053}$ & tcab0003c.h.2I_5.I.s.om.8 & $\begin{array}{l}\text { RT30_MOUSE (Q9D0G0) Mitochondrial 28S } \\
\text { ribosomal protein S30 (S30mt) (MRP-S30) }\end{array}$ & 104 & Omy. 16941 \\
\hline tcak000I.o.II & 204 & & tcaa000 I c.e.22_5.I.s.om.8 & $\begin{array}{l}\text { RL4A_XENLA (P08429) 60S ribosomal protein L4- } \\
\text { A (LIA) }\end{array}$ & 1161 & Omy.806 \\
\hline tcbk0003.k.18 & 205 & $\underline{B \times 874857}$ & tcay0003b.p.2I_3.I.s.om.8 & $\begin{array}{l}\text { RDH3_RAT (P50I69) Retinol dehydrogenase } 3 \\
\text { (EC I.I.I.I05) (Retinol dehydrogenase type I) } \\
\text { (RODH I) }\end{array}$ & 834 & Omy.2974 \\
\hline tcay0037.m.03 & 206 & BX319609 & tcay00I0b.o.II_3.I.s.om.8 & $\begin{array}{l}\text { GCST_MOUSE (Q8CFA2) } \\
\text { Aminomethyltransferase, mitochondrial precursor } \\
\text { (EC 2.I.2.I0) (Glycine cleavage system T protein) } \\
\text { (GCVT) }\end{array}$ & 1289 & Omy.634I \\
\hline IRT64O23_A_HI2 & 207 & $\underline{\mathrm{CA} 358010}$ & tcac0005c.k.07_3.I.s.om.8 & $\begin{array}{l}\text { KAD2_BOVIN (P08I66) Adenylate kinase } \\
\text { isoenzyme 2, mitochondrial (EC 2.7.4.3) (ATP- } \\
\text { AMP transphosphorylase) }\end{array}$ & 979 & Omy. 10546 \\
\hline tcbk0003.b. 17 & 208 & BX873257 & tcay00 I6b.b.23_3.I.s.om.8 & UNKNOWN & & Omy.8692 \\
\hline tcay0009.k.05 & 209 & $\mathrm{~B} \times 302690$ & $\begin{array}{l}\text { tcay0009b.k.05_3.I.s.om.8 } \\
\text { tcay0009b.k.05_5.I.s.om.8 }\end{array}$ & $\begin{array}{l}\text { HMI3_MOUSE (Q9D8V0) Minor } \\
\text { histocompatibility antigen HI3 (EC 3.4.99.-) (Signal } \\
\text { peptide peptidase) (Presenilin-like protein 3) }\end{array}$ & 1015 & Omy.24131 \\
\hline IRT36FI3_B_C07 & 210 & CA376488 & tcay0002b.c.06_3.I.s.om.8 & $\begin{array}{l}\text { TCPQ_PONPY (Q5RAPI) T-complex protein I, } \\
\text { theta subunit (TCP-I-theta) (CCT-theta) }\end{array}$ & 2366 & Omy.9154 \\
\hline tcaa000 I.g.20 & 211 & $\underline{B \times 073727}$ & $\begin{array}{l}\text { tcaa000 I c.g.20_3.I.s.om.8 } \\
\text { tcaa000 I c.g.20_5.I.s.om.8 }\end{array}$ & $\begin{array}{l}\text { TPM4_PIG (P67937) Tropomyosin alpha } 4 \text { chain } \\
\text { (Tropomyosin 4) }\end{array}$ & 744 & Omy.20509 \\
\hline tcbk0034.1.08 & 212 & BX878414 & tcbk0003c.j.07_5.I.s.om.8 & $\begin{array}{l}\text { CMAH_BRARE (Q6GMLI) Cytidine } \\
\text { monophosphate-N-acetylneuraminic acid } \\
\text { hydroxylase (EC I.14.18.2) }\end{array}$ & 2024 & Omy.4470 \\
\hline tcay0031.j. 13 & 213 & $\mathrm{~B} \times 316758$ & tcaa0002c.f.05_3.I.s.om.8 & $\begin{array}{l}\text { TPM4_PIG (P67937) Tropomyosin alpha } 4 \text { chain } \\
\text { (Tropomyosin 4) }\end{array}$ & 772 & Omy.8952 \\
\hline tcbk0045.m.Il & 214 & $\underline{\mathrm{B} \times 884217}$ & tcbk0028c.k.18_5.I.s.om.8 & $\begin{array}{l}\text { GSTPI_CRIMI (P47954) Glutathione S-transferase } \\
\text { P (EC 2.5.I. I8) (GST class-pi) }\end{array}$ & 636 & Omy.20977 \\
\hline
\end{tabular}


Table 2: Differentially regulated clones belonging to cluster I. (Continued)

\begin{tabular}{|c|c|c|c|c|c|c|}
\hline tcbk0037.f.02 & 215 & BX889865 & tcbi0036c.0.04_5.1.s.om.8 & $\begin{array}{l}\text { ATIIB_HUMAN (Q9Y2G3) Probable } \\
\text { phospholipid-transporting ATPase IF (EC 3.6.3.I) }\end{array}$ & 1193 & Omy.18989 \\
\hline IRTI46H05_B_D03 & 216 & CA350003 & tcbk0038c.p.05_5.I.s.om.8 & $\begin{array}{l}\text { HSP47_CHICK (PI373I) } 47 \text { kDa heat shock } \\
\text { protein precursor }\end{array}$ & 904 & Omy.24697 \\
\hline IRTI38MI5_A_G08 & 217 & CA386530 & & UNKNOWN & & \\
\hline IRTI29OII_A_H06 & 218 & CA385378 & CA385378.I.s.om.8 & $\begin{array}{l}\text { JPH2_HUMAN (Q9BR39) Junctophilin-2 } \\
\text { (Junctophilin type 2) (JP-2) }\end{array}$ & 554 & \\
\hline IRTI48PI3_B_H07 & 219 & CA368032 & CA350754.1.s.om.8 & CI0I0_HUMAN (Q9NZB2) Protein C9orfI0 & 103 & \\
\hline tcbk0039.a.06 & 220 & BX886884 & tcbk0007c.f.07_5.I.s.om.8 & $\begin{array}{l}\text { MDPI_PIG (P224I2) Microsomal dipeptidase } \\
\text { precursor (EC 3.4.I3.19) (MDP) } \\
\text { (Dehydropeptidase-I) (Renal dipeptidase) (RDP) }\end{array}$ & 1230 & Omy.21182 \\
\hline
\end{tabular}

\section{Identity of differentially expressed cDNAs}

The rainbow trout (Oncorhynchus mykiss) genome has not been sequenced and the number of characterized rainbow trout proteins and mRNAs is limited. The identity of studied transcripts was therefore based on the most significant hit obtained after performing a BlastX search against the SwissProt database. For the clones belonging to cluster 13 , the results of this blast search is presented in tables 2, 3, 4. For each clone, the identity of the best hit in SwissProt and the score value of the BlastX comparison are given. However, this similarity search was performed using all EST sequences available in public databases and not using fully characterized cDNAs displaying the full coding sequence of the transcript. For some of the clones spotted on the trout array, the corresponding mRNA was previously characterized and made available in public databases. The identity of those clones is therefore unambiguous. In contrast, for some other clones, the best hit in SwissProt only gives significant, but incomplete, information. This is especially true for protein family members for which only a phylogenetic analysis will allow a more relevant identification of the gene. However, the name of the best hit was used in the text for clarity reasons.

\section{Cluster I}

This large cluster of 32 clones (\# 189-220) was characterized by a clear under expression at the time of oocyte maturation. Among those 32 clones, 29 belonged to a UniGene cluster and 30 had a significant hit in Swiss-Prot (Table 2). Two clones (\#196 and 198) corresponded to rainbow trout ovarian P450 aromatase (cyp19a1) and therefore belonged to the same UniGene cluster (Omy. 241). Similarly, clones \# 199 and 200 belonged to UniGene cluster Omy.4204 and exhibited sequence similarity with bovine vitamin K-dependent protein S precursor. In addition, one clone (\# 202) corresponding to rainbow trout cyp1a3 (EC 1.14.14.1), was identified while another clone (\# 194) was most similar to rat CYP2J3. Finally, this cluster also included clones exhibiting sequence similarity with zebrafish cytidine monophosphate- $\mathrm{N}$-acetylneuraminic acid hydroxylase (cmah) (\# 212), salmon
NADPH - cytochrome P450 reductase (\# 192) and Glutathione S-transferase (\# 214). Within cluster 1, cyp19a1 (clones \# 196 and 198), vitamin K-dependent protein S precursor (clones \# 199 and 200) and cmah (clone \# 212) genes were kept for real-time PCR analysis.

\section{Cluster 2}

This very large cluster of 44 clones (\# 222-265) was characterized by a sharp over expression at the time of meiosis resumption. Among the 44 clones present in this cluster, 30 belonged to a UniGene cluster (Table 3). In addition, 39 clones exhibited a significant hit in SwissProt while 5 clones had no significant sequence similarities with known genes (Table 3). Within this cluster, several genes exhibited inflammation or ovulation-related functions. Thus some of the clones exhibited sequence similarities with human chemokine cxcl14 (clone \# 250), clawed frog adam22 (clone \# 258) and coagulation factor V (cf5) (clone \# 235). In addition, one clone (\# 245) exhibited strong sequence similarity with human angiotensin-converting enzyme 2 precursor (ace2). Two clones (\# 238 and 239) exhibited strong sequence similarity with salmon (Oncorhynchus keta) vasotocin-neurophysin (avt) and isotocin-neurophysin respectively. Finally, cluster 3 also contained clones exhibiting sequence similarity with, human Forkhead box protein O3A and human pendrin, also know as solute carrier family 26 member $4(\operatorname{slc} 26)$ (clone \# 236). Within cluster 2, cxcl14, adam22, slc26, avt, ace2 and $c f 5$ genes were kept for real-time PCR analysis.

\section{Cluster 3}

This small cluster of 14 clones (\# 296-309) was characterized by an over expression occurring earlier than for the genes belonging to cluster 3. Among those 14 clones, 12 belonged to a UniGene cluster and 11 had a significant hit in SwissProt (Table 4). Two clones (\# 305 and 306) were most similar to rat and human aquaporin 4 (aqp4) respectively. These 2 clones belonged to the same UniGene cluster (Omy.23866). In addition, one clone (\# 296) was most similar to mouse serine protease 23 (sp23). Within cluster 3, $a q p 4$ and $s p 23$ genes were kept for real-time PCR analysis. 
Table 3: Differentially regulated clones belonging to cluster 2

\begin{tabular}{|c|c|c|c|c|c|c|}
\hline Clone name & \# & GenBank & Sigenae Contig & swissprot_hit_description & Score & Unigene \\
\hline IRT85J04_D_E02 & 222 & CA345139 & CA345I39.1.s.om. 8 & UNKNOWN & & \\
\hline IRT62P05_B_H03 & 223 & CA352834 & CA352834.I.s.om.8 & $\begin{array}{l}\text { TIMI4_BRARE (Q6PBT7) Mitochondrial import } \\
\text { inner membrane translocase subunit TIMI4 (DnaJ } \\
\text { homolog subfamily C member 19) }\end{array}$ & 525 & Omy. 10044 \\
\hline IRTI24G08_C_D04 & 224 & CA359690 & tcay0005b.b.16_3.I.s.om.8 & $\begin{array}{l}\text { CITE2_HUMAN (Q99967) Cbp/p300-interacting } \\
\text { transactivator } 2 \text { (MSG-related protein I) (MRGI } \\
\text { protein) (P35srj) }\end{array}$ & 208 & Omy.6626 \\
\hline tcay00I3.c.09 & 225 & BX305023 & tcay00I3b.c.09_3.I.s.om.8 & CALDI_HUMAN (Q05682) Caldesmon (CDM) & 298 & Omy.9824 \\
\hline IRTIIOO02_C_HOI & 226 & CA366638 & CA366638.I.s.om.8 & $\begin{array}{l}\text { FTHFD_PONPY (Q5RFM9) I0- } \\
\text { formyltetrahydrofolate dehydrogenase (EC I.5.I.6) } \\
\text { (I0-FTHFDH) (Aldehyde dehydrogenase I family } \\
\text { member } \mathrm{LI})\end{array}$ & 755 & \\
\hline tcad0009.n. 15 & 227 & $\underline{B \times 081106}$ & tcad0009a.n.15_3.I.s.om.8 & $\begin{array}{l}\text { GPX4_PIG (P36968) Phospholipid hydroperoxide } \\
\text { glutathione peroxidase, mitochondrial precursor } \\
\text { (EC I.11.1.12) (PHGPx) (GPX-4) }\end{array}$ & 633 & Omy. 18352 \\
\hline tcac0005.m.05 & 228 & $\underline{B \times 083339}$ & tcac0005c.m.05_3.I.s.om.8 & $\begin{array}{l}\text { CP8BI_MOUSE (O88962) Cytochrome P450 8BI } \\
\text { (EC I.I4.-.) (CYPVIIIBI) }\end{array}$ & 466 & Omy. 1855 \\
\hline tcay0037.g.24 & 229 & BX320606 & tcay0037b.g.24_3.1.s.om.8 & $\begin{array}{l}\text { NOE2_HUMAN (O95897) Noelin-2 precursor } \\
\text { (Olfactomedin-2) }\end{array}$ & 571 & Omy.278 \\
\hline IRTI48F22_D_CII & 230 & CA368I4I & CA368I4I.I.s.om.8 & ETS2_CHICK (PI0I57) C-ETS-2 protein & 654 & \\
\hline IRT4II23_A_EI2 & 231 & $\overline{\text { CA } 376743}$ & CA376743.I.s.om. 8 & UNKNOWN & & \\
\hline tcbk00I3.j.22 & 232 & BX872432 & tcbk0006c.I.19_5.I.s.om.8 & $\begin{array}{l}\text { GPC3_HUMAN (P5 I654) Glypican-3 precursor } \\
\text { (GTR2-2) (MXR7) }\end{array}$ & 300 & Omy.254I7 \\
\hline tcba0030.f.0I & 233 & $\underline{B \times 865931}$ & tcay000Ib.n.04_3.I.s.om.8 & $\begin{array}{l}\text { BASI_HUMAN (P356|3) Basigin precursor } \\
\text { (CDI47 antigen) (Leukocyte activation antigen } \\
\text { M6) (Collagenase stimulatory factor) }\end{array}$ & 427 & Omy.19589 \\
\hline IRTI64G02_C_D0I & 234 & $\underline{\text { CA387850 }}$ & tcbk006 I c.m.06_5.I.s.om.8 & $\begin{array}{l}\text { SGK2_HUMAN (Q9HBY8) Serine/threonine- } \\
\text { protein kinase Sgk2 (EC 2.7.I.37) (Serum/ } \\
\text { glucocorticoid regulated kinase 2) }\end{array}$ & 1247 & Omy.9898 \\
\hline tcbk0057.a.03 & 235 & $\underline{B \times 879767}$ & tcba0016c.m.19_5.I.s.om.8 & $\begin{array}{l}\text { FA5_BOVIN (Q28I07) Coagulation factor } V \\
\text { precursor (Activated protein C cofactor) }\end{array}$ & 832 & Omy.1636I \\
\hline tcbk0013.j.13 & 236 & $\underline{B \times 873066}$ & tcbk0013c.j.13_5.I.s.om.8 & $\begin{array}{l}\text { PEND_HUMAN (O435II) Pendrin (Sodium- } \\
\text { independent chloride/iodide transporter) (Solute } \\
\text { carrier family } 26 \text { member } 4 \text { ) }\end{array}$ & 521 & \\
\hline IRT38LI2_D_F06 & 237 & CA377239 & CA377239.I.s.om.8 & DMD_CANFA (O97592) Dystrophin & 660 & \\
\hline IRT34L03_B_F02 & 238 & CA375992 & tcai0003a.h.04_5.I.s.om.8 & $\begin{array}{l}\text { NEU3_ONCKE (PI604I) Vasotocin-neurophysin } \\
\text { VT I precursor }\end{array}$ & 716 & Omy. 12737 \\
\hline IRTII3L09_B_F05 & 239 & CA365239 & tcbk0019c.d.02_5.I.s.om.8 & $\begin{array}{l}\text { NEUI_ONCKE (Q9II66) Isoticin-neurophysin IT } \\
\text { I }\end{array}$ & 875 & Omy.13912 \\
\hline tcbk0048.p. 10 & 240 & BX884149 & tcbk0048c.p.10_5.I.s.om.8 & COLL4_MIMIV (Q5UPS7) Collagen-like protein 4 & 224 & Omy. 14306 \\
\hline tcbk0046.i. 17 & 241 & BX884287 & tcbk0046c.i.17_5.I.s.om.8 & $\begin{array}{l}\text { COPTI_MOUSE (Q8K2II) High-affinity copper } \\
\text { uptake protein I (CTRI) }\end{array}$ & 640 & \\
\hline tcbk0004.a.22 & 242 & $\underline{B \times 876662}$ & tcbk0004c.a.22_5.I.s.om.8 & $\begin{array}{l}\text { RGSI8_HUMAN (Q9NS28) Regulator of G- } \\
\text { protein signaling I8 (RGSI8) }\end{array}$ & 467 & Omy. 15619 \\
\hline tcba0003.a.09 & 243 & BX857105 & tcav0003c.k.16_3.I.s.om.8 & UNKNOWN & & Omy. 11100 \\
\hline tcba0030.e. 12 & 244 & $\underline{B \times 866986}$ & tcay00Il lb.j.07_5.I.s.om.8 & $\begin{array}{l}\text { RNF24_HUMAN (Q9Y225) RING finger protein } \\
24\end{array}$ & 286 & \\
\hline tcba0024.c. 13 & 245 & BX867294 & tcav0002c.k.18_3.I.s.om.8 & $\begin{array}{l}\text { ACE2_HUMAN (Q9BYFI) Angiotensin-converting } \\
\text { enzyme } 2 \text { precursor (EC 3.4.17.-) }\end{array}$ & 1058 & Omy.5193 \\
\hline IRTI05A23_A_AI2 & 246 & CA363171 & tcad0009a.b.12_3.1.s.om.8 & $\begin{array}{l}\text { GA45B_HUMAN (O75293) Growth arrest and } \\
\text { DNA-damage-inducible protein GADD45 }\end{array}$ & 563 & Omy.24221 \\
\hline tcbk0035.k.02 & 247 & BX885992 & tcbk002I c.h.17_5.I.s.om.8 & $\begin{array}{l}\text { FOXO3_HUMAN (O43524) Forkhead box } \\
\text { protein O3A }\end{array}$ & 880 & Omy.21283 \\
\hline IRTI48EII_A_C06 & 248 & CA367914 & tcay0003b.j.08_3.I.s.om.8 & $\begin{array}{l}\text { FOXO3_HUMAN (O43524) Forkhead box } \\
\text { protein O3A }\end{array}$ & 692 & Omy.25I25 \\
\hline tcbk0048.o.16 & 249 & BX885768 & tcbk0048c.o.16_5.I.s.om.8 & SMOO_HUMAN (P538I4) Smoothelin & 717 & \\
\hline tcba0028.m.20 & 250 & $\underline{B \times 868653}$ & tcav000I c.p.02_3.I.s.om.8 & $\begin{array}{l}\text { SCYBE_HUMAN (O957I5) Small inducible } \\
\text { cytokine BI4 precursor (CXCLI4) }\end{array}$ & 319 & Omy.2735 \\
\hline tcbk0053.e.07 & 251 & $\underline{\mathrm{B} X 879710}$ & tcbk0053c.e.07_5.I.s.om.8 & $\begin{array}{l}\text { LFC_TACTR (P28I75) Limulus clotting factor C } \\
\text { precursor (EC 3.4.21.84) (FC) }\end{array}$ & 183 & \\
\hline tcba0018.p.09 & 252 & BX864334 & tcba0018c.p.09_5.I.s.om.8 & $\begin{array}{l}\text { SGK2_HUMAN (Q9HBY8) Serine/threonine- } \\
\text { protein kinase Sgk2 (EC 2.7.I.37) }\end{array}$ & 1407 & Omy. 16859 \\
\hline
\end{tabular}


Table 3: Differentially regulated clones belonging to cluster 2 (Continued)

\begin{tabular}{|c|c|c|c|c|c|c|}
\hline tcba00I3.e.II & 253 & $\underline{B \times 863135}$ & tcba00|3c.e.II_5.I.s.om.8 & $\begin{array}{l}\text { RAMPI_RAT (Q9JJ74) Receptor activity-modifying } \\
\text { protein I precursor }\end{array}$ & 400 & \\
\hline tcba0016.h.07 & 254 & BX863955 & tcay0023b.e.18_3.I.s.om.8 & $\begin{array}{l}\text { ACY3_HUMAN (Q96HD9) Aspartoacylase-2 (EC } \\
\text { 3.5.I.I5) (Aminoacylase-3) (ACY-3) (Acylase III) } \\
\text { (Hepatitis C virus core-binding protein I) } \\
\text { (HCBPI) }\end{array}$ & 695 & Omy. 12550 \\
\hline tcba0028.o.19 & 255 & BX866157 & tcay00I3b.p.20_3.I.s.om.8 & VISLI_RAT (P62762) Visinin-like protein I (VILIP) & 967 & Omy. 19419 \\
\hline IRTI06P06_D_H03 & 256 & CA365853 & tcba0005c.a.0I_5.I.s.om.8 & $\begin{array}{l}\text { MAFB_RAT (P54842) Transcription factor MafB } \\
\text { (MAFI) }\end{array}$ & 210 & Omy.24386 \\
\hline IRT98J03_B_E02 & 257 & CA357072 & tcay0038b.i.24_5.I.s.om.8 & $\begin{array}{l}\text { PNPH_BOVIN (P55859) Purine nucleoside } \\
\text { phosphorylase (EC 2.4.2.1) }\end{array}$ & 964 & Omy. I5824 \\
\hline IRTI06OI9_A_HIO & 258 & CA363I58 & CA363I58.I.s.om.8 & $\begin{array}{l}\text { ADA22_XENLA (O42596) ADAM } 22 \text { precursor } \\
\text { (MDCI Ib) (MDCII.2) }\end{array}$ & 889 & \\
\hline IRT62L08_D_F04 & 259 & CA352881 & tcac0002c.j.24_3.I.s.om.8 & $\begin{array}{l}\text { TPPI_CANFA (Q9XSB8) Tripeptidyl-peptidase I } \\
\text { precursor (EC 3.4.14.9) }\end{array}$ & 599 & Omy.8262 \\
\hline IRT44OII_A_H06 & 260 & CA379089 & tcay00I4b.n.20_3.I.s.om.8 & $\begin{array}{l}\text { PSD2_HUMAN (QI3200) 26S proteasome non- } \\
\text { ATPase regulatory subunit } 2 \text { (Tumor necrosis } \\
\text { factor type I receptor associated protein 2) (55.II } \\
\text { protein) }\end{array}$ & 1152 & Omy.1526I \\
\hline IRT30DI5_B_B08 & 261 & CA372310 & CA3723I0.1.s.om.8 & $\begin{array}{l}\text { KPCD_CANFA (Q5PU49) Protein kinase C, delta } \\
\text { type (EC 2.7.I.-) (nPKC-delta) }\end{array}$ & 932 & \\
\hline tcbk0050.j.02 & 262 & BX890245 & tcbk0050c.j.02_5.1.s.om.8 & DMD_HUMAN (PII532) Dystrophin & 1196 & \\
\hline IRT3IHI2_D_D06 & 263 & CA375388 & tcay0024b.g.05_3.I.s.om.8 & UNKNOWN & & Omy.407I \\
\hline tcba00I4.c. 14 & 264 & $\underline{B \times 863437}$ & tcav0005c.h.17_3.I.s.om.8 & $\begin{array}{l}\text { ELOVI_MOUSE (Q9JLJ5) Elongation of very long } \\
\text { chain fatty acids protein I }\end{array}$ & 187 & Omy.229I5 \\
\hline tcad0006.j.09 & 265 & BX077787 & $\begin{array}{l}\text { tcad0006a.j.09_5.I.s.om.8 } \\
\text { tcad0006a.j.09_3.I.s.om.8 }\end{array}$ & UNKNOWN & & Omy. 10230 \\
\hline
\end{tabular}

\section{Real-time PCR analysis}

For all the genes selected for the real-time PCR analysis, a similar up or down regulation was observed between microarray and real-time PCR experiments.

\section{Under expressed genes during oocyte maturation}

We observed a dramatic under expression of aromatase (cyp19a1, clones \# 196 and 198) in the ovary during the preovulatory period (Figure 2). The mRNA abundance of cyp19a gene during oocyte maturation was more than 200 times lower than during late vitellogenesis. In addition, successive decreases of cyp19a gene expression levels were observed during post-vitellogenesis and during oocyte maturation (Figure 2). The mRNA abundance of vitamin K-dependent protein S precursor gene (clones \# 199 and 200) was lower during oocyte maturation than during late or post-vitellogenesis. In contrast, no significant differences were observed between late and post-vitellogenesis (Figure 2). A similar expression profile was observed for Cytidine monophosphate-N-acetylneuraminic acid hydroxylase (cmah) gene (Figure 2).

\section{Over expressed genes during oocyte maturation}

We observed a strong over expression of aquaporin 4 (aqp4) gene during post-vitellogenesis and at the time of oocyte maturation (Figure 3 ). The mRNA abundance of aqp4 gene exhibited a 6-fold increase during post-vitellogenesis and a further 12-fold increase during oocyte maturation. In addition, the mRNA abundance of pendrin (slc26) gene exhibited a 1500-fold increase during oocyte maturation while no significant differences were observed between late and post-vitellogenesis. Similarly, vasotocin (avt) mRNA abundance exhibited a 500-fold increase at the time of oocyte maturation (Figure 3). Angiotensinconverting enzyme 2 (ace2) gene expression levels exhibited a 215-fold increase between late vitellogenesis and oocyte maturation (Figure 3). A similar profile was observed for the chemokine $\operatorname{cxcl} 14$ gene. The mRNA abundance of this gene exhibited a 35-fold increase between late vitellogenesis and oocyte maturation (Figure 3 ). The mRNA abundance of coagulation factor $\mathrm{V}$ (cf5) gene exhibited a 177-fold increase between late or postvitellogenesis and oocyte maturation while adam 22 mRNA abundance exhibited a 6-fold increase between late or post-vitellogenesis and oocyte maturation (Figure 3 ). Finally, the mRNA abundance serine protease 23 (sp23) gene monitored during oocyte maturation was higher than in the late vitellogenic ovary. However, this difference was not significantly different $(\mathrm{p}=0.078)$.

\section{Control gene}

The mRNA abundance of elongation factor 1 alpha $(e f 1 \alpha)$, a translation regulatory protein commonly used as a stable reference, did not exhibit any significant difference over the preovulatory period (Figure 3 ).

\section{Discussion}

\section{Microarray analysis efficiency and reliability}

The hybridization of radiolabeled cDNAs with cDNAs deposited on nylon membranes has been used for several 
Table 4: Differentially regulated clones belonging to cluster 3.

\begin{tabular}{|c|c|c|c|c|c|c|}
\hline Clone name & \# & GenBank & Sigenae contig & swissprot_hit_description & Score & Unigene \\
\hline tcav0003.I.0I & 296 & $\underline{B \times 087643}$ & $\begin{array}{l}\text { tcav0003c.I.0I_3.I.s.om.8 } \\
\text { tcav0003c.I.0I_5.I.s.om.8 }\end{array}$ & $\begin{array}{l}\text { PRS23_MOUSE (Q9D6X6) Serine protease } 23 \\
\text { precursor (EC 3.4.21.-) }\end{array}$ & 265 & Omy.8589 \\
\hline tcbk0008.n.08 & 297 & $\underline{B \times 87 \mid 436}$ & tcac0002c.a.0I_3.I.s.om.8 & UNKNOWN & & Omy. 10950 \\
\hline $\operatorname{tcad} 0003 . \mathrm{m} .13$ & 298 & BX075335 & $\begin{array}{l}\text { tcad0003a.m.13_5.I.s.om.8 } \\
\text { tcad0003a.m.13_3.1.s.om.8 }\end{array}$ & $\begin{array}{l}\text { PPTI_MACFA (Q8HXW6) Palmitoyl-protein } \\
\text { thioesterase I precursor (EC 3.1.2.22) }\end{array}$ & 1110 & Omy.37I7 \\
\hline IRT65FI0_D_C05 & 299 & CA35317I & tcab000Ic.m.15_5.I.s.om.8 & $\begin{array}{l}\text { APOCI_MOUSE (P34928) Apolipoprotein C-I } \\
\text { precursor (Apo-Cl) (ApoC-l) }\end{array}$ & 123 & Omy.20585 \\
\hline tcay0008.f. 19 & 300 & $\underline{\mathrm{B} X 301535}$ & $\begin{array}{l}\text { tcay0008b.f.19_3.I.s.om.8 } \\
\text { tcay0008b.f.19_5.I.s.om.8 }\end{array}$ & $\begin{array}{l}\text { CLDII_MOUSE (Q6077I) Claudin-II } \\
\text { (Oligodendrocyte transmembrane protein) }\end{array}$ & 331 & Omy.5138 \\
\hline IRT63M2I_A_GII & 301 & CA357931 & tcaa0002c.j.15_3.1.s.om.8 & $\begin{array}{l}\text { ION3_CARAU (PI8520) Intermediate filament } \\
\text { protein ON3 }\end{array}$ & $|33|$ & Omy.40 \\
\hline IRT67D22_D_BII & 302 & CA360891 & CA36089I.I.s.om.8 & $\begin{array}{l}\text { PTPRF_HUMAN (PI0586) Receptor-type tyrosine- } \\
\text { protein phosphatase F precursor (EC 3.I.3.48) } \\
\text { (LAR protein) (Leukocyte antigen related) }\end{array}$ & 1466 & Omy.24653 \\
\hline IRT63G2I_A_DII & 303 & CA357905 & tcad0003a.m.13_3.I.s.om.8 & $\begin{array}{l}\text { PPTI_MACFA (Q8HXW6) Palmitoyl-protein } \\
\text { thioesterase I precursor (EC 3.I.2.22) }\end{array}$ & 1110 & Omy.5643 \\
\hline IRT35EI0_C_C05 & 304 & $\underline{\mathrm{CA} 376275}$ & CA376275.I.s.om.8 & UNKNOWN & & \\
\hline tcbk0056.f.03 & 305 & BX880542 & tcbk0056c.f.03_5.I.s.om.8 & $\begin{array}{l}\text { AQP4_RAT (P47863) Aquaporin-4 (AQP-4) } \\
\text { (WCH4) (Mercurial-insensitive water channel) }\end{array}$ & 442 & Omy.23866 \\
\hline tcbk0036.e.03 & 306 & $\underline{B \times 885214}$ & tcbk0036c.e.03_5.I.s.om.8 & $\begin{array}{l}\text { AQP4_HUMAN (P55087) Aquaporin-4 (AQP-4) } \\
\text { (WCH4) (Mercurial-insensitive water channel) }\end{array}$ & 1071 & Omy.23866 \\
\hline tcay0007.b.05 & 307 & $\underline{\mathrm{B} X 300900}$ & tcay0007b.b.05_3.I.s.om.8 & HEPH_RAT (Q920H8) Hephaestin precursor & 1085 & Omy.25044 \\
\hline tcac0006.o.01 & 308 & $\mathrm{~B} \times 085175$ & $\begin{array}{l}\text { tcac0006c.o.0I_3.I.s.om.8 } \\
\text { tcac0006c.0.0I_5.I.s.om.8 }\end{array}$ & $\begin{array}{l}\text { LTBP2_MOUSE (O08999) Latent transforming } \\
\text { growth factor-beta-binding protein } 2 \text { precursor }\end{array}$ & 328 & \\
\hline tcbk0044.e.02 & 309 & BX889077 & tcay0040b.e.18_5.I.s.om.8 & UNKNOWN & & Omy.23994 \\
\hline
\end{tabular}

decades. However, the use of nylon cDNA microarrays is not very common in comparison to glass slide microarray technology. Nevertheless, this technology has successfully been used for several years $[27,35]$. In the present study we used similar CDNA manufacturing and hybridization protocols. While most of the 9152 clones used to generate the microarray putatively correspond to distinct genes, a small proportion of genes are represented by 2 distinct clones (e.g clones belonging to the same UniGene cluster). In our data, it is noteworthy that those clones are usually found in the same gene clusters (e.g clones \#196 and 198, \#199 and 200, \#305 and 306). Since the position of clones in the clustering analysis is based on the correlation between their profiles, this indicates that they display very similar expression profiles. In addition, for all genes selected for real-time PCR analysis, the over or under expression observed was always consistent with microarray data. Furthermore, the expression of ef $1 \alpha$, a widely used reference gene, was stable over the preovulatory period. Together, these observations suggest that our overall microarray analysis is extremely robust and reliable.

\section{Identities of identified genes and putative involvement in preovulatory ovarian functions}

In the present study, we identified 310 genes exhibiting a differential expression during the preovulatory period. Among them, 220 were down-regulated during oocyte maturation while 90 exhibited an opposite pattern. However, because we decided, as a first step, to focus our anal- ysis on the genes exhibiting the most differential regulation in the periovulatory period, we only present the identity of the 90 genes belonging to 3 specific clusters exhibiting the most remarkable patterns. Among those 90 transcripts we have chosen to discuss the most informative or novel genes based on their identities and/or putative involvement in the rainbow trout preovulatory ovarian functions.

\section{Estrogen synthesis}

Among the 32 clones belonging to cluster 1, two clones correspond to rainbow trout ovarian aromatase (cyp19a1). The real-time PCR study confirmed that cyp19a1 was dramatically under expressed during the preovulatory period. This observation is in total agreement with existing data on aromatase expression during this period $[19,36]$. In addition, a clone putatively encoding for a NADPH-cytochrome P450 reductase (EC 1.6.2.4) was also located in cluster 1 . The aromatase enzyme complex is formed from 2 principal protein components. CYP19a1 contains the catalytic domain that binds C19 steroid substrates in the proximity of the heme prosthetic group critical in the activation of molecular oxygen and subsequent substrate hydroxylation. The other essential component is the redox partner flavoprotein, NADPH cytochrome P450 reductase. Interestingly, present data show that both transcripts exhibited an under expression during the rainbow trout preovulatory period, although it should be confirmed that the identified clone is coding for 


\section{cyp19a1}

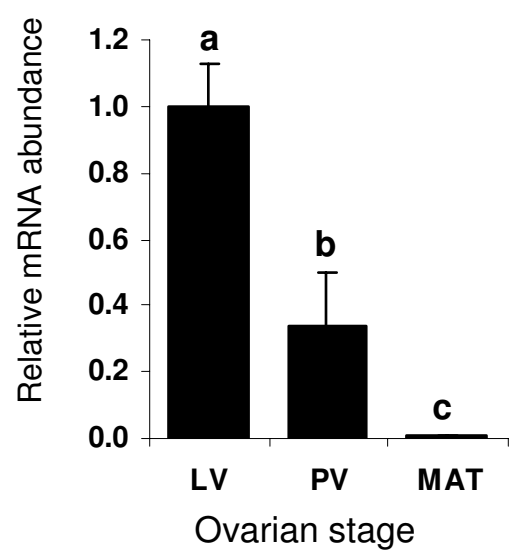

proteins

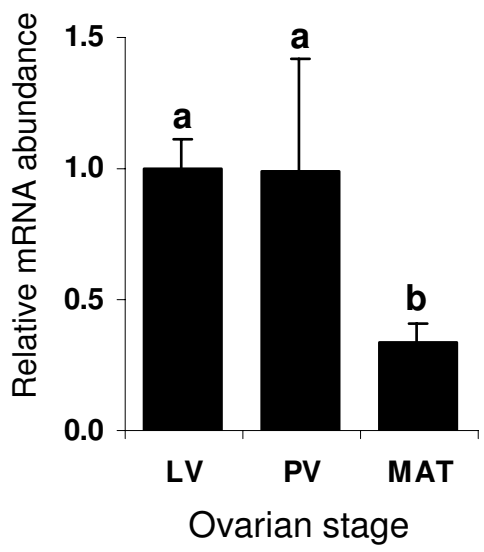

cmah

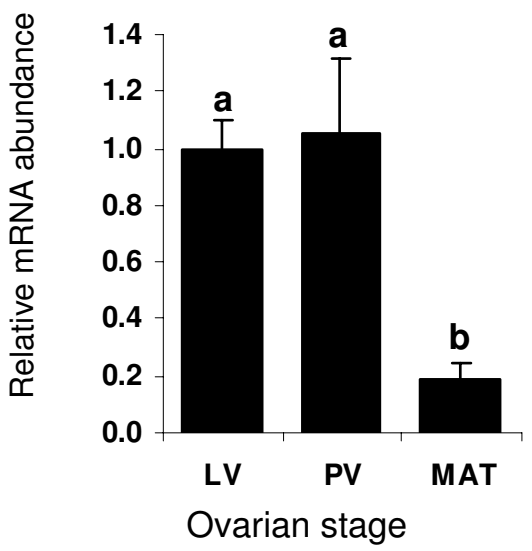

Figure 2

Ovarian expression profiles of aromatase (cyp/9al), vitamin K dependent protein S (proteinS) and cytidine monophosphate-Nacetylneuraminic acid hydroxylase $(\mathrm{cmah})$ genes during rainbow trout late oogenesis (mean $\pm \mathrm{SEM}$ ). Ovaries were sampled from separate females during late vitellogenesis $(\mathbf{L V}, \mathbf{N}=6)$, post-vitellogenesis $(\mathbf{P V}, \mathbf{N}=6)$ and oocyte maturation $(\mathbf{M A T}, \mathbf{N}$ $=6$ ). The mRNA abundance of each gene was determined by real-time PCR and normalized to the abundance of I8S. Abundance was arbitrarily set to I for LV stage and data are expressed as a percentage of the transcript abundance at this stage. Bars sharing the same letter $(s)$ are not significantly different $(p<0.05)$.

the oxydoreductase protein involved in the aromatase complex.

\section{Other cytochrome $\mathrm{P} 450$ genes}

Two other cytochrome P450 genes, exhibiting similar expression profiles were found in the same cluster. One clone (\# 194) was most similar to rat cytochrome P450 2J3 while the other one (\# 202) putatively corresponded to rainbow trout cytochrome P450 1A3 (cyp1a3). Cytochrome P450 1A proteins are ubiquitous proteins that have been associated with the detoxification of several organic compounds such as PCB (polychlorinated biphenyl), PAH (polyaromatic hydrocarbons), and dioxin [37]. In fish, these compounds are able to induce cyp1a gene expression in a variety of tissues. In the rainbow trout immature ovary, a constitutive expression of CYP1A protein was previously reported [38]. Together, previous and present observations suggest that a CYP1A-related detoxification activity in the rainbow trout ovary. From the under expression of cyp1a3 gene observed in the ovary immediately prior to ovulation we could speculate that a decrease of the detoxification activity of the ovary is required before the beginning of the ovulation process. In addition, it was previously shown in rat C6 glioma cells that epoxygenases could inhibit prostaglandin E2 production [39]. Interestingly, C6 cells express epoxygenase
mRNAs, CYP1A1, CYP2B1 and CYP2J3, which convert arachidonic acid to epoxyeicosatrienoic acids; those epoxyeicosatrienoic acid being able to inhibit the activity of cyclooxygenase [39]. The role of prostaglandins in the ovulatory process has been thoroughly studied (see [40] for review). Thus, in rainbow trout, prostaglandin F2 $\alpha$ was able to induce in vitro ovulation $[21,41]$. Therefore, the observed down-regulation of $c y p 1 a 1$ and $c y p 2 j 3$ genes in the ovary prior to ovulation is therefore totally consistent with available data on the participation of prostaglandins in the ovulatory process.

\section{lon/water transport genes}

In the present transcriptomic analysis, two aquaporin 4 (aqp4) clones were found in cluster 3. Real-time PCR data confirmed that rainbow trout aqp4 gene exhibited a strong over expression in the preovulatory ovary. In mammals, AQP4 is also known as mercurial insensitive water channel (MIWC). It was previously shown that water permeability was strongly increased in African clawed frog oocytes expressing MIWC [42]. In marine fish, a strong oocyte hydration occurs during oocyte maturation $[43,44]$. In addition, it was recently shown that this oocyte hydration involves an aquaporin1-like protein in seabream [45]. In freshwater species, data on oocyte hydration is more controversial. However, a limited but 
ace2

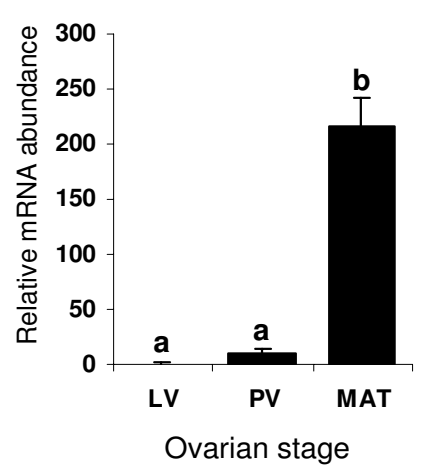

aqp4

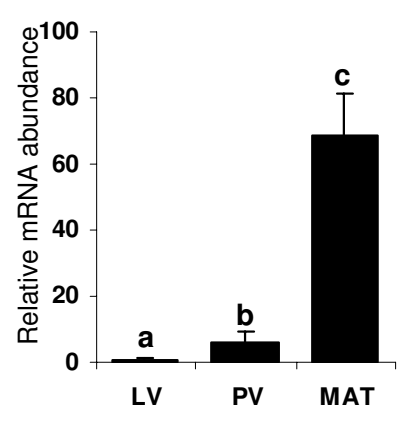

Ovarian stage

sp23

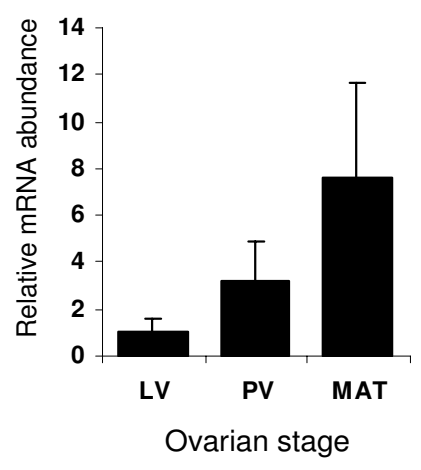

cf5

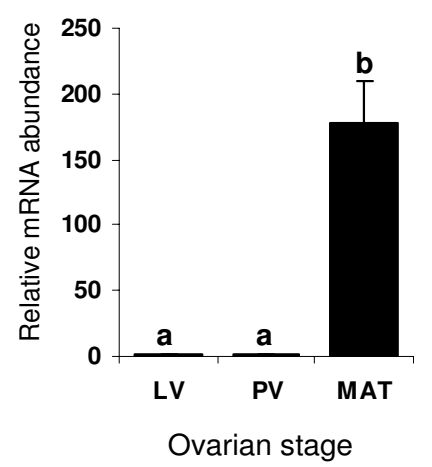

s/c26

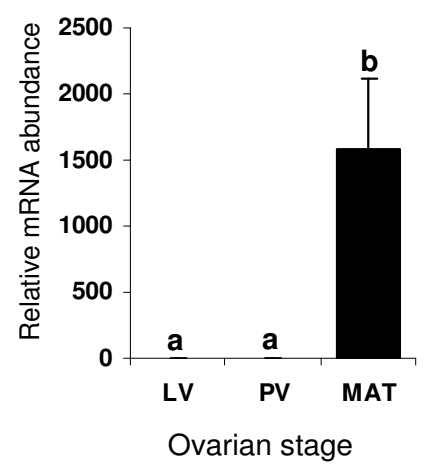

adam22

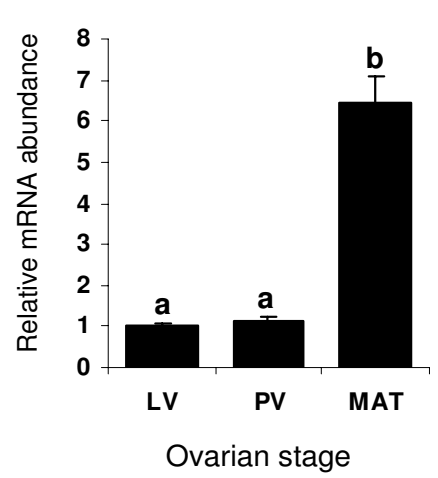

cxcl14

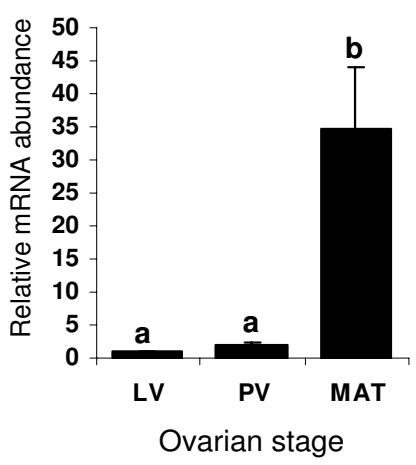

avt
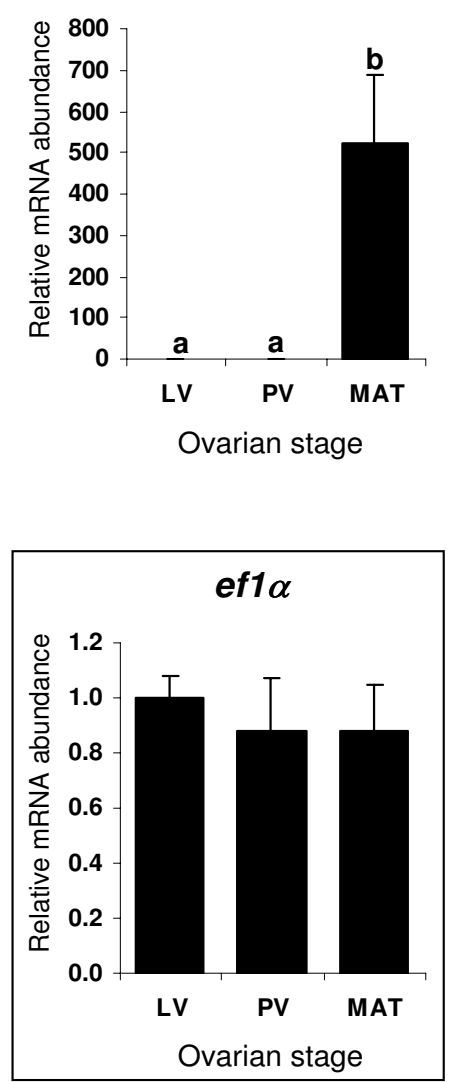

\section{Figure 3}

Ovarian expression profiles of angiotensin-converting enzyme 2 (ace2), coagulation factor $\mathrm{V}(\mathrm{cf} 5$ ), CXC chemokine LI4 ( $c x c l$ ) , aquaporin 4 (aqp4), pendrin (slc26), vasotocin (avt), serine protease 23 (sp23), ADAM22 (adam22), and elongation factor I alpha $(\mathrm{efl} \alpha)$ genes during rainbow trout late oogenesis (mean $\pm \mathrm{SEM}$ ). Ovaries were sampled from separate females during late vitellogenesis ( $L V, N=6)$, post-vitellogenesis $(P V, N=6)$ and oocyte maturation $(M A T, N=6)$. The mRNA abundance of each gene was determined by real-time PCR and normalized to the abundance of I8S. Abundance was arbitrarily set to I for LV stage and data are expressed as a percentage of the transcript abundance at this stage. Bars sharing the same letter(s) are not significantly different $(p<0.05)$. 
significant hydration was also observed in several freshwater species including rainbow trout [46]. Our data suggest that, similarly to marine species, the oocyte hydration occurring during oocyte maturation could also be aquaporin-mediated in freshwater species such as rainbow trout. In addition to aqp4 gene, we also observed a dramatic over expression of slc26 gene at the time of meiosis resumption. Solute carrier family 26 member 4 (slc26) is also known as sodium-independent chloride/ iodide transporters or pendrin. The over expression of slc26 gene at the time of oocyte maturation is dramatic, as demonstrated by real-time PCR. Together, the strong upregulation of aqp4 and slc26 genes at the time of meiosis resumption stresses the importance of water and ion transports in the rainbow trout preovulatory ovarian functions. In marine species, the major oocyte hydration occurring before ovulation is probably important for adjusting egg buoyancy. In contrast, in freshwater species laying demersal eggs such as rainbow trout, it has been hypothesized that the limited (25\%) oocyte hydration occuring before ovulation could be necessary for the completion of the ovulation process [46]. Thus, the increase of oocyte volume could facilitate the rupture of the follicular walls and subsequently, the release of the oocyte from its follicular layers.

The neurophysial hormones arginine vasotocin (AVT) and isotocin (IT) are the fish counterparts of argininevasopressin and oxytocin respectively. Vasotocin precursor and isotocin precursor $\mathrm{CDNAs}$ were previously cloned in several fish species including chum salmon $[47,48]$. In fish, AVT is involved in several physiological processes including water conservation and excretion of electrolytes [49]. However, existing data in fish correspond to the local effect, in various tissues, of circulating AVT [49]. Surprisingly, we observed that AVT precursor (avt) mRNA is expressed in the rainbow trout preovulatory ovary. To the best of our knowledge, there is no evidence of non-neural expression of avt mRNA in fish. In addition, it is noteworthy that we also observed a similar over expression of isotocin mRNA precursor in the ovary at the time of oocyte maturation. Further investigations are needed to elucidate the role of AVT and IT in the trout preovulatory ovarian functions.

\section{Inflammation- or ovulation-related genes}

Ovulation is a complex process resulting in the release of the oocyte from surrounding follicular layers. Since the early eighties, the similarities between ovulatory and inflammatory processes have been thoroughly discussed [50-52] and it is now well accepted that mammalian ovulation is an inflammatory-like reaction. In fish, despite numerous studies on the hormonal control of spawning, the ovulatory process has been far less documented.
In mammals, ovulation is accompanied by broad-spectrum proteolysis and the implication of several classes of proteases is well documented (see [53] for review). In salmonid fish, several proteases have been identified in the periovulatory ovary [54]. In mammals, there is evidence that mature ovarian follicles contain proteolytic enzymes, including serine proteases. Indeed, serine proteases have been implicated in both ovulatory and inflammatory reactions (see [50] for review). In the present study, serine protease 23 (sp23) gene appears progressively up-regulated during the preovulatory period. To our knowledge, sp23 gene expression was never reported in the periovulatory ovary of any vertebrate species. However, we could speculate that this protease participates in the rainbow trout ovulatory process. Interestingly, our data showed that adam 22 metalloprotease-disintegrin gene was sharply up-regulated at the time of oocyte maturation. The metalloprotease-disintegrin protein family (also known as ADAMs: A Disintegrin And Metalloproteinases) is thought to function in cell-cell interactions and in the proteolysis of luminal or extracellular protein domains. In mammals, several ADAMs family members are involved in the ovulatory process. In brook trout (Salvelinus fontinalis), metalloprotease activity increases in the ovary prior to ovulation $[8,9]$. Together, these observations also suggest that adam 22 also participates in the rainbow trout ovulatory process.

Mammalian CXC chemokines, named after a conserved pattern of conserved cysteine residues, have been initially identified as potent mediators of neutrophil chemotaxis $[55,56]$ and are also involved in chemotaxis of monocytes and lymphocytes. They have also been implicated in angiogenesis and, later, in a large variety of functions $[57,58]$. In mammals, 16 CXC have been described. In Fish, however, several CXC have been identified but only CXCL12 and CXCL14 exhibit unambiguous orthologues [59]. In the present study, we showed that $\operatorname{cxcl14}$ gene expression strongly increases during the preovulatory period. In catfish, RT-PCR data showed that $\mathrm{cxcl14}$ gene was expressed in a wide variety of tissues, including the ovary [60]. In carp, quantitative PCR data showed that $\mathrm{cxcl14}$ was predominantly expressed in the brain [61]. Despite its good conservation throughout vertebrate evolution [59], the number of studies addressing the in vivo role(s) of CXCL14 is limited. As a consequence, a lot of information is still unavailable in fish. In a murine model used to study Crohn's disease, cxcl14 expression is induced during inflammation [62]. Together, these observations suggest that $\mathrm{cxcl14}$ gene expression induction contributes to the inflammatory-like events occurring in the rainbow trout at the time of ovulation. To date the participation of this gene in preovulatory ovarian functions was unsuspected. 
In mammals, coagulation factor $\mathrm{V}$ participates in the coagulation process. In zebrafish, a coagulation factor $\mathrm{V}(c f 5)$ cDNA was previously characterized [63]. According to these authors, several lines of evidences including biochemical and phylogenetic analyses suggest that the modern coagulation pathways found in mammals could also be functional in fish. Furthermore, it was previously shown that cultured rabbit macrophages were able to generate factor $\mathrm{V}$ procoagulant activity [64]. In the present study, we observed a dramatic increase of $c f 5$ gene expression in the ovary during oocyte maturation. However, no significant difference was observed between late and postvitellogenesis. From these observations we could speculate that, immediately prior to ovulation, the trout ovary secretes coagulation factors in order to prevent bleeding from ruptured ovarian follicles at the time of ovulation. Interestingly, the transcriptomic analysis showed that a transcript exhibiting sequence similarity with clotting factor C (Clone \# 251, Table 3) was also over expressed immediately prior to ovulation.

Angiotensin-converting enzyme (ACE) cleaves Angiotensin I (Ang I) to form Angiotensin II (Ang II). Angiotensin-converting enzyme 2 (ACE2) is a recently described ACE homolog [65]. Both ACE and ACE2 are zinc-dependent peptidases of the M2-metalloprotease family. Within the renin-angiotensin system (RAS), ACE2 competes with ACE because it is capable of hydrolyzing Ang I into the nonapeptide Ang(1-9) [65]. In humans, ace 2 gene expression was predominantly detected by Northern blot analysis in kidney, heart and testis $[65,66]$. In addition, a moderate expression was also observed in several other tissues including the ovary [66]. Using semiquantitative RT PCR, a wide distribution was observed in rat tissues [67]. In mammals, previous observations suggested that the renin-angiotensin system was functional in the ovary. In cattle, a greater expression of Ang II was observed in large follicles. In addition, several lines of evidence supported the idea of Ang II in blocking the inhibitory effect of theca cells on meiosis resumption of bovine oocytes [68]. In brook trout (Salvelinus fontinalis) salmon Ang I and human Ang II were both able to increase the level of in vitro spontaneous ovulation [69]. In the present transcriptomic study, we observed a dramatic increase of ace 2 gene expression during the preovulatory period. This observation was confirmed by real-time PCR data. Together, these observations suggest that the dramatic upregulation of ace 2 gene immediately prior to ovulation is important for the ovulatory process. In mammals, little is know about the role of ACE2 in the ovary. However, it is known in mammals that ACE2 can function as an Ang II degrading enzyme, forming the vasodilatator peptide Ang(1-7) [70,71]. Interestingly, a local vasodilatation is a key characteristics of the inflammatory response that is also observed during the mammalian ovulatory process (see [50] for review). Therefore, it can be hypothesized that the observed increase of ace 2 gene expression in the trout preovulatory participates in the vascular dynamics changes that are putatively occurring during the ovulatory process.

\section{Genes involved in the synthesis of egg components}

Cytidine monophosphate-N-acetylneuraminic acid hydroxylase (CMAH) is the key enzyme for the synthesis of $\mathrm{N}$-glycolylneuraminic acid. In salmonid eggs, cortical alveoli contain polysialoglycoproteins (PSGP). In rainbow trout, it was previously shown that those PSGP contain $N$-glycolylneuraminic acid residues [72]. In the present study we observed a significant decrease of cmah gene expression at the time of oocyte maturation. While the presence of cmah gene expression in the ovary is totally consistent with the presence of $\mathrm{N}$-glycolylneuraminic acid in rainbow trout cortical alveoli content, it seems however difficult to speculate on the dynamics of PSGP accumulation in the oocytes.

\section{Conclusion}

Our observations further confirmed that a progressive shut down of estrogen synthesis genes expression occurs in the ovary prior to meiosis resumption. In addition to already well studied genes such as aromatase, the present work shows that other genes exhibit a similar down-regulation, thus suggesting their participation in the preovulatory decrease of circulating estrogen levels.

In addition, we observed a strong up-regulation of ion/ water transport genes in the preovulatory ovary. The identity of those genes is consistent with the recent identification of aquaporin mediated mechanisms in the fish oocyte hydration process and further supports the recent description of a limited but significant oocyte hydration occurring in the rainbow trout preovulatory ovary.

Finally, in addition to oocyte hydration-related genes, we also observed a strong over expression of several genes such proinflammatory factors, coagulation/clotting factors, vasodilatation factors and proteases in the ovary immediately prior to ovulation. Together, these observations suggest that, similarly to the theory developed in mammals, fish ovulation could also be compared ton an inflammatory-like reaction. In addition, the identification of those genes will allow specific studies leading to a better understanding of the ovulatory process in fish.

In the future, a global analysis of differentially regulated genes, based on their ontologies, is needed to satisfyingly describe preovulatory ovarian mechanisms. In addition, a cellular localization of gene expression will contribute in the understanding of their respective roles in the preovulaory ovarian physiology. Nevertheless, the present study 
clearly demonstrates that distinct (i.e. steroidogenic, proteolytic, proinflammatory) but concomitant events occur in the preovulatory ovary. Together, all those events concur to achieve the same goal which is the release, at the time of ovulation, of a fully competent oocyte, ready to be fertilized.

\section{Authors' contributions}

JM performed the microarray analysis. TN performed the real-time PCR analysis. AF participated in the writing of the manuscript and in the design and coordination of the study. JB supervised the study, participated in the microarray and real-time PCR analyses, performed data mining analysis and drafted the manuscript. All authors read and approved the final manuscript.

\section{Acknowledgements}

This work was funded by an INRA-AGENAE-IFOP grant to JB. The authors thank INRA-GADIE (Jouy en Josas, France) resource center for manufacturing and providing micro-arrays and the INRA-SIGENAE group (Toulouse, France) for bioinformatic support. The authors also thank all INRA experimental facility personnel (Sizun and Rennes) for animal care.

\section{References}

I. Goetz FW: Hormonal control of oocyte final maturation and ovulation in fishes. In Fish Physiology Edited by: Hoar WS, Randall DJ, Donaldson EM. New York: Academic Press; 1983:1 I7-170.

2. Goetz FW, Garczynski M: The ovarian regulation of ovulation in teleost fish. Fish Physiology and Biochemistry 1997, 17:33-38.

3. Jalabert B, Fostier A, Breton B, Weil C: Oocyte Maturation in Vertebrates. In Vertebrate Endocrinology, Fundamentals and Biomedical Implications Edited by: Pang P, Schreibman M. New York: Academic Press; 1991:23-90.

4. Patino R, Sullivan CV: Ovarian follicle growth, maturation, and ovulation in teleost fish. Fish Physiology and Biochemistry 2002, 26:57-70.

5. Yamashita M, Mita K, Yoshida N, Kondo T: Molecular mechanisms of the initiation of oocyte maturation: general and speciesspecific aspects. Prog Cell Cycle Res 2000, 4: I I 5-I 29.

6. Patino R, Thomas P, Yoshizaki G: Ovarian follicle maturation and ovulation: an integrated perspective. Fish Physiology and Biochemistry 2003, 28:305-308.

7. Berndtson AK, Goetz FW, Duman P: In vitro ovulation, prostaglandin synthesis, and proteolysis in isolated ovarian components of yellow perch (Perca flavescens): effects of $17 \alpha, 20 \beta$ dihydroxy-4-pregnen-3-one and phorbol ester. Gen Comp Endocrinol 1989, 75:454-465.

8. Berndtson AK, Goetz FW: Metallo-protease activity increases prior to ovulation in brook trout (Salvelinus fontinalis) and yellow perch (Perca flavescens) follicle walls. Biol Reprod 1990, 42:391-398.

9. Berndtson AK, Goetz FW: Protease activity in brook trout (Salvelinus fontinalis) follicle walls demonstrated by substratepolyacrylamide gel electrophoresis. Biol Reprod 1988, 38:511-516.

10. Bobe J, Goetz FW: A novel osteopontin-like protein is expressed in the trout ovary during ovulation. FEBS Lett $200 \mathrm{I}$, 489: $119-124$.

II. Bobe J, Goetz FW: A SI00 homologue mRNA isolated by differential display PCR is down-regulated in the brook trout (Salvelinus fontinalis) post-ovulatory ovary. Gene 2000, 257:187-194.

12. Bobe J, Goetz FW: A tumor necrosis factor decoy receptor homologue is Up-regulated in the brook trout (Salvelinus fontinalis) ovary at the completion of ovulation. Biol Reprod 2000, 62:420-426.

13. Garczynski MA, Goetz FW: Molecular characterization of a ribonucleic acid transcript that is highly up-regulated at the time of ovulation in the brook trout (Salvelinus fontinalis) ovary. Biol Reprod 1997, 57:856-864.

14. Tada T, Endo M, Hirono I, Takashima F, Aoki T: Differential expression and cellular localization of activin and inhibin mRNA in the rainbow trout ovary and testis. Gen Comp Endocrinol 2002, I 25:142-149.

15. Wang Y, Ge W: Spatial expression patterns of activin and its signaling system in the zebrafish ovarian follicle: evidence for paracrine action of activin on the oocytes. Biol Reprod 2003, 69:1998-2006.

16. Choi CY, Takashima F: Molecular cloning and hormonal control in the ovary of connexin 31.5 mRNA and correlation with the appearance of oocyte maturational competence in red seabream. J Exp Biol 2000, 203:3299-3306.

17. Yoshizaki G, Patino R, Thomas P: Connexin messenger ribonucleic acids in the ovary of Atlantic croaker: molecular cloning and characterization, hormonal control, and correlation with appearance of oocyte maturational competence. Biol Reprod 1994, 5 I:493-503.

18. Bobe J, Maugars G, Nguyen T, Rime H, Jalabert B: Rainbow trout follicular maturational competence acquisition is associated with an increased expression of follicle stimulating hormone receptor and insulin-like growth factor $\mathbf{2}$ messenger RNAs. Mol Reprod Dev 2003, 66:46-53.

19. Bobe J, Nguyen T, Jalabert B: Targeted Gene Expression Profiling in the Rainbow Trout (Oncorhynchus mykiss) Ovary During Maturational Competence Acquisition and Oocyte Maturation. Biol Reprod 2004, 71:73-82.

20. MacKenzie S, Iliev D, Liarte C, Koskinen H, Planas JV, Goetz FW, Molsa H, Krasnov A, Tort L: Transcriptional analysis of LPSstimulated activation of trout (Oncorhynchus mykiss) monocyte/macrophage cells in primary culture treated with cortisol. Mol Immunol 2006, 43:1340-1348.

21. Jalabert B: Production of fertilizable oocytes from follicles of rainbow trout (Salmo gairdneri) following in vitro maturation and ovulation. Ann Biol Anim Biochim Biophys 1978, 1 8:46I-470.

22. Jalabert $B$, Fostier $A$ : The follicular sensitivity in vitro to maturation-inducing hormones in rainbow trout, Salmo gairdneri: role of oestradiol- I 7 3 . Aquaculture 1984, 43: I- II.

23. INRA-GADIE [http://www-crb.jouy.inra.fr/]

24. Aegerter S, Baron D, Carpentier C, Chauvigne F, Dantec C, Estampes A, Goupil A-S, Jumel A, Jutel I, Mazurais D, Melaine N, Montfort J, Bobe J, Chardon P, Chevalet C, Fauconneau B, Fostier A, Govoroun M, Le Cam A, Le Gac F, Klopp C, Panserat S, Piumi F, Rallière C, Rescan $P-Y$, Guiguen $Y$ : The INRA AGENAE program and the Agenae trout EST collections: first results applied to fish physiology research. Comp Biochem Physiol A 2004, I 37: I 35-I4I.

25. Nguyen C, Rocha D, Granjeaud S, Baldit M, Bernard K, Naquet P, Jordan BR: Differential gene expression in the murine thymus assayed by quantitative hybridization of arrayed cDNA clones. Genomics 1995, 29:207-216.

26. GEO [http://www.ncbi.nlm.nih.gov/projects/geo/]

27. Bertucci F, Bernard K, Loriod B, Chang YC, Granjeaud S, Birnbaum $D$, Nguyen C, Peck K, Jordan BR: Sensitivity issues in DNA arraybased expression measurements and performance of nylon microarrays for small samples. Hum Mol Genet 1999, 8:1715-1722

28. Tusher VG, Tibshirani R, Chu G: Significance analysis of microarrays applied to the ionizing radiation response. Proc Natl Acad Sci USA 200I, 98:51 16-5I21.

29. Eisen MB, Spellman PT, Brown PO, Botstein D: Cluster analysis and display of genome-wide expression patterns. Proc Natl Acad Sci USA 1998, 95:|4863-|4868.

30. Rexroad CE, Lee Y, Keele JW, Karamycheva S, Brown G, Koop B, Gahr SA, Palti Y, Quackenbush J: Sequence analysis of a rainbow trout cDNA library and creation of a gene index. Cytogenetic and Genome Research 2003, 102:347-354.

31. Sigenae [http://www.sigenae.org]

32. Gish W, States DJ: Identification of protein coding regions by database similarity search. Nat Genet 1993, 3:266-272.

33. Swiss-Prot [http://www.expasy.org/sprot/]

34. UniGene [http://www.ncbi.nlm.nih.gov/UniGene/]

35. Bertucci F, Finetti P, Rougemont J, Charafe-Jauffret E, Cervera N, Tarpin C, Nguyen C, Xerri L, Houlgatte R, Jacquemier J, Viens P, Birnbaum D: Gene expression profiling identifies molecular sub- 
types of inflammatory breast cancer. Cancer Res 2005, 65:2170-2178

36. Tanaka M, Telecky TM, Fukada S, Adachi S, Chen S, Nagahama Y: Cloning and sequence analysis of the CDNA encoding P-450 aromatase (P450arom) from a rainbow trout (Oncorhynchus mykiss) ovary; relationship between the amount of P450arom mRNA and the production of oestradiol- 17 beta in the ovary. J Mol Endocrinol 1992, 8:53-61.

37. Mansuy $D$ : The great diversity of reactions catalyzed by cytochromes P450. Comp Biochem Physiol C Pharmacol Toxicol Endocrinol 1998, I 21:5-14.

38. Weber LP, Diamond SL, Bandiera SM, Janz DM: Expression of HSP70 and CYPIA protein in ovary and liver of juvenile rainbow trout exposed to beta-naphthoflavone. Comp Biochem Physiol C Toxicol Pharmacol 2002, I 3 I:387-394.

39. Toriniwa $Y$, Lv X, Kodama Y, Ohizumi $Y$, Yoshida M, Nakahata N Participation of epoxygenase activation in saikogenin $D$ induced inhibition of prostaglandin $\mathrm{E}(2)$ synthesis. J Pharm Pharmacol 2006, 58:859-866.

40. Goetz FW, Berndtson AK, Ranjan M: Ovulation: Mediators at the ovarian level. In Vertebrate Endocrinology: Fundamentals and Biomedical Implications Edited by: Pang PKT, Schreibman MP. San Diego, CA: Academic Press; 1991:127-203.

4l. Jalabert B, Szöllösi D: In vitro ovulation of trout oocytes: effect of prostaglandins on smooth muscle-like cells of the theca. Prostaglandins 1975, 9:765-78.

42. Hasegawa H, Ma T, Skach W, Matthay MA, Verkman AS: Molecular cloning of a mercurial-insensitive water channel expressed in selected water-transporting tissues. I Biol Chem 1994 269:5497-5500.

43. Selman K, Wallace RA: Oogenesis in Fundulus heteroclitus. III. Vitellogenesis. J Exp Zool 1983, 226:44I-457.

44. Watanabe WO, Kuo C-M: Water and ion balance in hydrating oocytes of the grey mullet, Mugil cephalus (L.) during hormone-induced final maturation. J Fish Biol 1986, 28:425-437.

45. Fabra M, Raldua D, Power DM, Deen PM, Cerda J: Marine fish egg hydration is aquaporin-mediated. Science 2005, 307:545.

46. Milla $S$, Jalabert $B$, Rime $H$, Prunet $P$, Bobe J: Hydration of rainbow trout oocyte during meiotic maturation and in vitro regulation by 17,20 beta\}-dihydroxy-4-pregnen-3-one and cortisol. J Exp Biol 2006, 209: I |47-II 56.

47. Heierhorst J, Mahlmann S, Morley SD, Coe IR, Sherwood NM, Richter $D$ : Molecular cloning of two distinct vasotocin precursor cDNAs from chum salmon (Oncorhynchus keta) suggests an ancient gene duplication. FEBS Lett 1990, 260:301-304.

48. Hyodo $S$, Kato $Y$, Ono $M$, Urano $A$ : Cloning and sequence analyses of cDNAs encoding vasotocin and isotocin precursors of chum salmon, Oncorhynchus keta: evolutionary relationships of neurohypophysial hormone precursors. J Comp Physiol [B] 1991, 160:601-608.

49. Balment RJ, Lu W, Weybourne E, Warne JM: Arginine vasotocin a key hormone in fish physiology and behaviour: A review with insights from mammalian models. Gen Comp Endocrinol 2006, 147:9-16.

50. Espey LL: Ovulation as an inflammatory reaction - A hypothesis. Biol Reprod 1980, 22:73-106.

5I. Espey LL: Current status of the hypothesis that mammalian ovulation is comparable to an inflammatory reaction. Biol Reprod 1994, 50:233-238.

52. Richards JS, Russell DL, Ochsner S, Espey LL: Ovulation: new dimensions and new regulators of the inflammatory-like response. Annu Rev Physiol 2002, 64:69-92.

53. Ohnishi J, Ohnishi E, Shibuya H, Takahashi T: Functions for proteinases in the ovulatory process. Biochim Biophys Acta 2005, 1751:95-109.

54. Hajnik CA, Goetz FW, Hsu SY, Sokal N: Characterization of a ribonucleic acid transcript from the brook trout (Salvelinus fontinalis) ovary with structural similarities to mammalian adipsin/complement factor $D$ and tissue kallikrein, and the effects of kallikrein-like serine proteases on follicle contraction. Biol Reprod 1998, 58:887-897.

55. Walz A, Peveri $P$, Aschauer $H$, Baggiolini M: Purification and amino acid sequencing of NAF, a novel neutrophil-activating factor produced by monocytes. Biochem Biophys Res Commun | 987, | 49:755-76|.
56. Yoshimura T, Matsushima K, Tanaka S, Robinson EA, Appella E, Oppenheim JJ, Leonard EJ: Purification of a human monocytederived neutrophil chemotactic factor that has peptide sequence similarity to other host defense cytokines. Proc Natl Acad Sci USA 1987, 84:9233-9237.

57. Mackay CR: Chemokines: immunology's high impact factors. Nat Immunol 200I, 2:95-10I.

58. Onuffer JJ, Horuk R: Chemokines, chemokine receptors and small-molecule antagonists: recent developments. Trends Pharmacol Sci 2002, 23:459-467.

59. Huising MO, Stet RJ, Kruiswijk CP, Savelkoul HF, Lidy Verburg-van Kemenade BM: Molecular evolution of CXC chemokines: extant CXC chemokines originate from the CNS. Trends Immunol 2003, 24:307-3I3.

60. Baoprasertkul P, He C, Peatman E, Zhang S, Li P, Liu Z: Constitutive expression of three novel catfish CXC chemokines: homeostatic chemokines in teleost fish. Mol Immunol 2005, 42: I355-I 366.

61. Huising MO, van der MT, Flik G, Verburg-van Kemenade BM: Three novel carp CXC chemokines are expressed early in ontog. eny and at nonimmune sites. Eur J Biochem 2004, 27 I:4094-4 I 06.

62. Abad C, Juarranz Y, Martinez C, Arranz A, Rosignoli F, Garcia-Gomez M, Leceta J, Gomariz RP: cDNA array analysis of cytokines, chemokines, and receptors involved in the development of TNBS-induced colitis: homeostatic role of VIP. Inflamm Bowel Dis 2005, II:674-684.

63. Hanumanthaiah R, Day K, Jagadeeswaran P: Comprehensive analysis of blood coagulation pathways in teleostei: evolution of coagulation factor genes and identification of zebrafish factor VIlli. Blood Cells Mol Dis 2002, 29:57-68.

64. Rothberger H, McGee MP: Generation of coagulation factor $\mathbf{V}$ activity by cultured rabbit alveolar macrophages. J Exp Med 1984, 160:1880-1890

65. Donoghue M, Hsieh F, Baronas E, Godbout K, Gosselin M, Stagliano N, Donovan M, Woolf B, Robison K, Jeyaseelan R, Breitbart RE, Acton S: A novel angiotensin-converting enzyme-related carboxypeptidase (ACE2) converts angiotensin I to angiotensin I-9. Circ Res 2000, 87:EI-E9.

66. Tipnis SR, Hooper NM, Hyde R, Karran E, Christie G, Turner Al: A human homolog of angiotensin-converting enzyme. Cloning and functional expression as a captopril-insensitive carboxypeptidase. I Biol Chem 2000, 275:33238-33243.

67. Riviere G, Michaud A, Breton C, VanCamp G, Laborie C, Enache M, Lesage J, Deloof S, Corvol P, Vieau D: Angiotensin-converting enzyme 2 (ACE2) and ACE activities display tissue-specific sensitivity to undernutrition-programmed hypertension in the adult rat. Hypertension 2005, 46: I 169-I I74.

68. Giometti IC, Bertagnolli AC, Ornes RC, da Costa LF, Carambula SF, Reis AM, de Oliveira JF, Emanuelli IP, Goncalves PB: Angiotensin II reverses the inhibitory action produced by theca cells on bovine oocyte nuclear maturation. Theriogenology 2005, 63:1014-1025.

69. Hsu S, Goetz FW: Angiotensins stimulate in vitro ovulation and contraction of brook trout (Salvelinus fontinalis) follicles. Fish Physiol Biochem 1992, 10:277-282.

70. Vickers C, Hales P, Kaushik V, Dick L, Gavin J, Tang J, Godbout K, Parsons T, Baronas E, Hsieh F, Acton S, Patane M, Nichols A, Tummino $P$ : Hydrolysis of biological peptides by human angiotensinconverting enzyme-related carboxypeptidase. I Biol Chem 2002, 277: | 4838-| 4843 .

71. Zisman LS, Keller RS, Weaver B, Lin Q, Speth R, Bristow MR, Canver $C C$ : Increased angiotensin-(I-7)-forming activity in failing human heart ventricles: evidence for upregulation of the angiotensin-converting enzyme Homologue ACE2. Circulation 2003, 108: $1707-1712$

72. Kitajima K, Inoue S, Inoue $Y$, Troy FA: Use of a bacteriophagederived endo- $\mathrm{N}$-acetylneuraminidase and an equine antipolysialyl antibody to characterize the polysialyl residues in salmonid fish egg polysialoglycoproteins. Substrate and immunospecificity studies. / Biol Chem 1988, 263:|8269-I8276. 